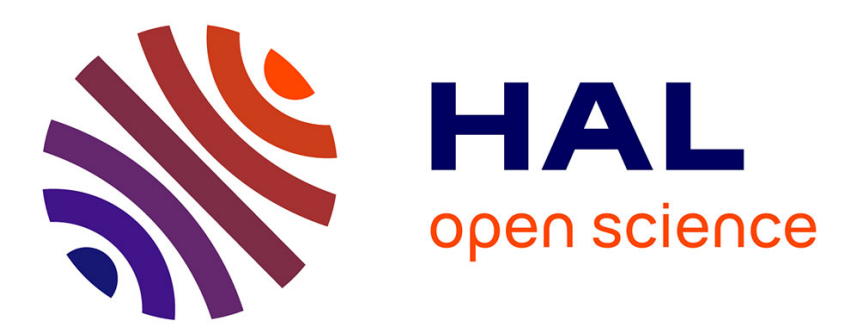

\title{
Functional and cellular localization diversity associated with Fukutin-related protein patient genetic variants
}

\author{
Sara F Henriques, Evelyne Gicquel, Justine Marsolier, Isabelle Richard
}

\section{To cite this version:}

Sara F Henriques, Evelyne Gicquel, Justine Marsolier, Isabelle Richard. Functional and cellular localization diversity associated with Fukutin-related protein patient genetic variants. Human Mutation, 2019, 40 (10), pp.1874-1885. 10.1002/humu.23827 . hal-02177499

\section{HAL Id: hal-02177499 \\ https://hal-univ-evry.archives-ouvertes.fr/hal-02177499}

Submitted on 2 Mar 2021

HAL is a multi-disciplinary open access archive for the deposit and dissemination of scientific research documents, whether they are published or not. The documents may come from teaching and research institutions in France or abroad, or from public or private research centers.
L'archive ouverte pluridisciplinaire HAL, est destinée au dépôt et à la diffusion de documents scientifiques de niveau recherche, publiés ou non, émanant des établissements d'enseignement et de recherche français ou étrangers, des laboratoires publics ou privés. 


\section{Human Mutation Human Mutation \\ Variation, Informatics, and Disease}

\section{Functional and cellular localization diversity associated with Fukutin related protein patient genetic variants}

\begin{tabular}{|c|c|}
\hline Journal: & Human Mutation \\
\hline Manuscript ID & humu-2018-0564.R2 \\
\hline Wiley - Manuscript type: & Research Article \\
\hline $\begin{array}{r}\text { Date Submitted by the } \\
\text { Author: }\end{array}$ & $n / a$ \\
\hline Complete List of Authors: & $\begin{array}{l}\text { Henriques, Sara; Genethon, INSERM UMR951 } \\
\text { Gicquel, Evelyne; Genethon, INSERM UMR951 } \\
\text { Marsolier, Justine; Genethon, INSERM UMR951 } \\
\text { Richard, Isabelle; Genethon, INSERM UMR951 Evry, Île-de-France, FR }\end{array}$ \\
\hline Key Words: & $\begin{array}{l}\text { FKRP, LGMD2I, dystroglycan, missense mutations, protein quality } \\
\text { control, glycosylation }\end{array}$ \\
\hline
\end{tabular}

\section{SCHOLARONE" \\ Manuscripts}




\title{
Functional and cellular localization diversity associated with
}

\section{Fukutin related protein patient genetic variants}

\author{
Sara F. Henriques ${ }^{1}$, Evelyne Gicquel $^{1}$, Justine Marsolier $^{1}$ and Isabelle Richard ${ }^{1}$ \\ 1 INTEGRARE Research Unit, UMR951, Généthon, INSERM, Université Evry Val \\ d’Essonne, Université Paris-Saclay, 91002, Evry, France
}

\section{Funding information}

Généthon is part of the Biotherapies Institute for Rare Diseases (BIRD) which is supported by the Association Française contre les Myopathies (AFM-Téléthon). SH was supported by a PhD fellowship from the University of Paris-Saclay. 


\begin{abstract}
Genetic variants in Fukutin related protein (FKRP), an essential enzyme of the glycosylation pathway of $\alpha$-dystroglycan, can lead to pathologies with different severities affecting the eye, brain and muscle tissues. Here, we generate an in vitro cellular system to characterize the cellular localization as well as the functional potential of the most common FKRP patient missense mutations. We observe a differential retention in the Endoplasmic Reticulum (ER), indication of misfolded proteins. We find data supporting that mutant proteins able to overcome this ER-retention through overexpression present functional levels comparable to the wild-type. We also identify a specific region in FKRP protein localized between residues 300 and 321 in which genetic variants found in patients lead to correctly localized proteins but which are nevertheless functionally impaired or catalytically dead in our model, indicating that this particular region might be important for the enzymatic activity of FKRP within the Golgi. Our system thus allows the functional testing of patient specific mutant proteins and the identification of candidate mutants to be further explored with the aim of finding pharmacological treatments targeting the protein quality control system.
\end{abstract}

\title{
Keywords
}

FKRP; LGMD2I; dystroglycan; genetic variants; missense mutations; protein quality control; glycosylation. 


\section{Introduction}

Muscular dystrophies are a group of monogenic diseases affecting the skeletal muscle and characterized by a progressive loss of the muscle mass. One substantial group of muscle dystrophies termed "dystroglycanopathies" encompasses different genetic pathologies, ultimately characterized by hypoglycosylation of the protein $\alpha$-dystroglycan ( $\alpha$-DG). This protein is a fundamental component of the dystrophin-associated glycoprotein complex (DGC) in the muscles and also plays additional important roles in other tissues such as the eye and brain. Through a complex and specific glycosylation of the protein, raising its weight from 70 to $156 \mathrm{kDa}$ in muscle (Barresi \& Campbell, 2006), the plasma membrane is anchored to different extracellular-matrix (ECM) components (Hohenester, Tisi, Talts, \& Timpl, 1999; Talts, Andac, Gohring, Brancaccio, \& Timpl, 1999; Tisi, Talts, Timpl, \& Hohenester, 2000), such as laminin in the cardiac and skeletal muscles (Ervasti \& Campbell, 1993). The connexion of the fibers to the ECM is crucial for membrane stabilization, especially during muscle contraction/relaxation cycles. In dystroglycanopathies, hypoglycosylation of $\alpha$-DG leads to disruption of plasma membrane attachment, to fragility of the tissue and therefore to a dystrophic process.

The genetic basis of dystroglycanopathies is very heterogeneous, reflecting the peculiar machinery of enzymes contributing to the glycosylation of $\alpha$-DG. At present, genetic variants in 17 different genes coding for enzymes of the $\alpha$-DG glycosylation pathway have been identified as being implicated in these disorders, which range from the severe WalkerWarburg Syndrome (WWS), Muscle-Eye-Brain disease (MEB) or Congenital Muscular Dystrophy (CMD) to the mildest Limb-Girdle Muscular Dystrophies (LGMDs). 
Genetic variants in the gene coding for Fukutin-related protein (FKRP) (FKRP; MIM\# 606596), one of the enzymes of the $\alpha$-DG glycosylation pathway, can lead to all the aforementioned pathologies (MIM\# 613153, 606612, 607155) (Beltran-Valero de Bernabe, 2004; Brockington et al., 2001; Richard, Laurent, Cirak, \& Vissing, 2016). FKRP protein is a type II transmembrane protein localized in the mid/trans-Golgi apparatus of the skeletal muscle cells (Alhamidi et al., 2011). It is characterized by a short cytoplasmic domain followed by transmembrane, stem and catalytic domains, the last one possessing a DxD amino-acid motif critical for the catalytic function of the protein (Esapa et al., 2002). FKRP was described as a transferase of ribitol-phosphate into the growing glycosylation chain using as substrate the precursor molecule CDP-ribitol, and acting in succession to another related enzyme of the pathway, Fukutin (FKTN) (FKTN; MIM\# 607440) (Gerin et al., 2016; Kanagawa et al., 2016). Of note, FKRP and FKTN were recently shown to act also as a CDPglycerol transferases, which inhibits the functional glycosylation of $\alpha$-DG (Imae et al., 2018).

The most common types of FKRP patient genetic variants are missense mutations, with, in particular, a high prevalence of a specific genetic variant, the NM_001039885.2:p.Leu276Ile (L276I) (Richard et al., 2016). Missense mutations, resulting in an amino-acid change, can lead to protein folding defects when the amino-acid properties are not preserved. These misfolded proteins can be detected and blocked by the quality control (QC) system of the cells and, specifically in the case of transmembrane and secretory proteins, be retained in the Endoplasmic reticulum (ER) and directed to premature degradation by the proteasome through the ER-associated degradation (ERAD) system. Interestingly, despite the presence of the genetic variant, a certain degree of biological activity of the protein can still be preserved, suggesting that "rescue" of these proteins from the strict QC surveillance and degradation systems could ameliorate the related pathology. Indeed, pharmacological treatments proved 
successful in vitro for the rescue of FKTN (Tachikawa, Kanagawa, Yu, Kobayashi, \& Toda, 2012) or of other mutated proteins of the DGC such as the sarcoglycans (Carotti et al., 2018; Soheili et al., 2012). Some of the most prevalent FKRP missense mutations have been described to be retained in the ER (Esapa et al., 2002; Esapa, McIlhinney, \& Blake, 2005; Keramaris-Vrantsis et al., 2007; Matsumoto et al., 2004; Torelli et al., 2005), leading to loss of function though cellular mislocalization from the Golgi, the cellular compartment where FKRP exerts its function. The functional potential of these ER-retained mutant proteins if properly rescued to the Golgi has not been assessed, a crucial characteristic to determine at the time when pharmacological treatments aiming to target the ERQC and ERAD systems are envisaged for patients. Beside these cases, other FKRP genetic variants were shown to be correctly localized in the Golgi compartment, some of which being implicated in severe phenotypes such as WWS (Keramaris-Vrantsis et al., 2007). The underlying explanation of the discrepancies between the correct localization and the severity of the phenotype has not been elucidated.

In this study, we addressed the current gap in knowledge about the functional potential of mutant proteins bearing some of the most common FKRP patient genetic variants. We developed heterologous models, which permitted the investigation of the subcellular localization and functional status of the disease-causing FKRP mutated proteins. We demonstrated that genetic variants observed to be retained in the ER can nevertheless be able to overcome this retention and present activity levels comparable to wild-type. In addition, we observed that some of the FKRP mutant proteins that correctly localize in the Golgi present either no or severely impaired function, indicating that the pathological mechanism of these FKRP genetic variants might correspond to a direct perturbation of the enzymatic function whereas the mutated protein is considered normal by the QC. Taken together, this data can 
bring important implications for the development of therapeutic strategies in FKRP deficiencies for which there is still no curative treatment, more specifically for patients affected by genetic variants leading to ER-retained but nonetheless functional proteins.

\section{Materials and methods}

2.1 Cloning and mutagenesis. The FKRP fusion protein comprising the human FKRP CCDS (Gene ID: 79147, NM_001039885.2, CCDS12691.1), the prototypical FLAG sequence (DYKDDDDK), a flexible type linker (3xGGGGS) (Chen, Zaro, \& Shen, 2013) and a mCherry fluorescent reporter sequence was synthesized and codon-optimized for human expression by GENEWIZ. The transgene was inserted into a lentivirus backbone plasmid under the transcriptional control of the CMV promoter. The final construct was named FKRPmCh. Mutagenesis was performed in FKRPmCh plasmid using the QuickChange XL Mutagenesis Kit (Agilent) according to the supplier's protocol with the mutant constructs differing from the wild-type only by the modification of the codon of the genetic variant.

2.2 Cell culture. Near-haploid human HAP1 cells are commercialized by Horizon Discovery $^{\mathrm{TM}}$. The HAP1 FKRP $_{\mathrm{KO}}$ cell line, bearing a 17 base-pair (bp) deletion in the endogenous FKRP gene, was available off-the-shelf (Product ID: HZGHC000726c009). The cells were grown in Iscove's Modified Dulbecco's Medium (IMDM) (Thermo Fisher Scientific) with $10 \%$ fetal bovine serum (FBS) (Thermo Fisher Scientific) and $10 \mu \mathrm{g} / \mathrm{ml}$ of Gentamicin (Thermo Fisher Scientific) and incubated at $37^{\circ} \mathrm{C}$ and atmospheric humidity of $5 \% \mathrm{CO}_{2}$. Cells were mycoplasma negative. 
2.3 Transfections and transductions. Cells were seeded in six or twelve well-plates at $60 \%$ confluence. Cells used for immuno-fluorescence (IF) staining were seeded on glass coverslips in the bottom of the well. Transfection of FKRPmCh plasmids were conducted using Turbofectin 8.0 reagent (Origene) for $48 \mathrm{~h}$ accordingly to the supplier's protocol and a Turbofectin/DNA ratio of 3: 1 with the same DNA concentrations. Transduction of lentiviral particles expressing FKRPmCh WT or mutant constructs were performed at multiplicity of infection (MOI) of three and in combination with Polybrene (6ug/mL; Sigma-Aldrich). Incubation with the viral particles was performed for $18 \mathrm{~h}$ at $37^{\circ} \mathrm{C}$ and $5 \% \mathrm{CO}_{2}$, after which the medium was replaced and the cells were kept at $37^{\circ} \mathrm{C}$ until further analysis.

2.4 Immuno-fluorescence confocal staining, acquisition and analysis. The IF staining for confocal microscopy was performed as follows: the cells were fixed in formaldehyde $3.7 \%$ (Sigma-Aldrich) for 15 minutes at room temperature. If permeabilization was required, Triton $\mathrm{X}-100 \quad 0.5 \%$ (Sigma-Aldrich) was used for $5 \mathrm{~min}$ at room temperature. Saturation was performed in PBS 20\% foetal bovine serum (FBS) for $1 \mathrm{~h}$ at room temperature. The primary antibodies Calnexin (Rabbit, ab22595, Abcam), GM130 (Mouse, 610822, BD-Biosciences), TGN46 (Sheep, AHP500GT, BioRad), $\alpha$-dystroglycan (IIH6; Mouse, sc-53987, Santa Cruz Biotechnology), $\beta$-integrin (Mouse, sc-13590, Santa Cruz Biotechnology) or Wheat Germ Agglutinin (WGA-Alexa Fluor ${ }^{\mathrm{TM}} 488$ Conjugate, W11261, Thermo Fisher Scientific) were added in the appropriate dilutions in PBS $2 \%$ FBS for $3 \mathrm{~h}$ at room-temperature or over-night at $4^{\circ} \mathrm{C}$. After three washes with PBS for 5 minutes, incubation with secondary antibodies Alexa Fluor ${ }^{\mathrm{TM}}-488$ and Alexa Fluor ${ }^{\mathrm{TM}}-594$ fluorescent-conjugated antibodies (Thermo Fisher Scientific) was performed in PBS 2\% FBS for $1 \mathrm{~h}$ at room-temperature in the dark. Three washes with PBS for 5 minutes were performed and the glass slides were mounted in DAPI Fluoromount-G ${ }^{\circledR}$ (CliniSciences) overnight at $4{ }^{\circ} \mathrm{C}$. For the endogenous FKRP protein 
labelling, the fluorescent signal amplification Tyramide SuperBoost Kit (Anti-rabbit Alexa Fluor ${ }^{\text {TM}}-488$, B40922, Thermo Fisher Scientific) was used accordingly to the supplier's protocol. Confocal images were taken using the Leica SP8 confocal microscope (Leica) at either the 40X, 63X or 100X oil-objectives. Bright-field images were taken using the Evos microscope (Thermo Fisher Scientific) at a 40X objective. Images were treated and analysed using ImageJ/Fiji software (Schindelin et al., 2012) and the Pearson's coefficients of correlation were calculated using the JACoP plugin (Bolte \& Cordelieres, 2006).

2.5 Flow cytometry staining, acquisition and analysis. The staining for flow cytometry was performed as follows: saturation was performed in cold PBS 2\% FBS + human FcR blocking agent (Miltenyi Biotec) for 20 minutes at $4^{\circ} \mathrm{C}$. The primary antibody $\alpha$-dystroglycan (IIH6; Mouse, sc-53987, Santa Cruz Biotechnology) was diluted at a ratio 1/20 in cold PBS 2\% FBS and incubated for 20 minutes at $4^{\circ} \mathrm{C}$. After one wash with cold PBS, incubation with the Goat anti-Mouse Alexa Fluor ${ }^{\mathrm{TM}}-488$ fluorescent-conjugated secondary antibody (Thermo Fisher Scientific) was performed in PBS $2 \%$ FBS for 20 minutes at $4{ }^{\circ} \mathrm{C}$ in the dark. Three washes with cold PBS were performed and the final cell pellets were ressuspended in cold PBS $2 \%$ FBS and kept in ice until further analysis. Positive (HAP1-WT) and negative (secondary

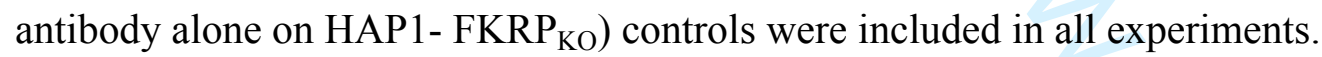

The CytoFLEX flow cytometer (Beckman Coulter) and the B525/40 BP (A488) and Y610/20 BP (mCherry) lasers were used with the same settings for all experiments. Flow cytometry data was treated and analysed using the Kaluza analysis software (Beckman Coulter). Flow cytometry values are presented as the integrated Mean Fluorescence Intensity (iMFI). iMFI is calculated as the MFI multiplied by the percentage of positive cells for the glycosylation (IIH6) signal within the mCherry positive cell population which equals correctly transfected cells. The iMFI $\alpha$-DG glycosylation values of patient fibroblasts by flow cytometry were 
shown to be closely related to the glycosylation levels in the corresponding muscle biopsies (Stevens et al., 2013). Flow cytometry values were normalized against the transduced FKRP WT construct in each independent experiment.

2.6 Prediction of functional impact of FKRP variants. The online predictor tools Polymorphism Phenotyping v2 (PolyPhen-2 (Adzhubei et al., 2010), http://genetics.bwh.harvard.edu/pph2/), Protein Variation Effect Analyzer (PROVEAN (Choi, Sims, Murphy, Miller, \& Chan, 2012), http://provean.jcvi.org/seq_submit.php) and MutationAssessor release 3 ((Reva, Antipin, \& Sander, 2011), http://mutationassessor.org/r3/) were used at the last current version (March 2019) and run with the default settings.

2.7 Data and statistical analysis. The GraphPad PRISM 7.01 program (GraphPad Software Inc.) was used for calculating statistics using unpaired t-test. The results represent the average \pm SEM of at least three independent experiments (cell culture, transfection/transduction and analysis performed in different days). P-values were calculated using the WT as control and P $<0.05$. Regression curves were calculated using a centred second order polynomial (quadratic) equation with ordinary fit parameters. $n s=$ non-significant, ${ }^{*} \mathrm{p} \leq 0.05,{ }^{*} \mathrm{p} \leq 0.01,{ }^{* * *} \mathrm{p} \leq 0.001$, $* * * * \mathrm{p} \leq 0.0001$

\section{Results}

\subsection{Cellular model validation}

In order to study the cellular consequences of FKRP patient genetic variants in vitro, we took advantage of the near-haploid HAP1 cell line as these cells were previously shown to support 
the complete $\alpha$-DG chain of glycosylation (Endo et al., 2015; Riemersma et al., 2015). To avoid interference by the endogenous FKRP protein, a CRISPR/Cas9-induced FKRP knockout $(\mathrm{KO})$ cell line was used (HAP1-FKRP $\mathrm{KO}_{\mathrm{KO}}$ ). Validation of the cellular model was performed by FKRP immuno-labelling and $\alpha$-DG glycosylation staining. Using an immuno-fluorescence (IF) amplification system, we demonstrated the absence of endogenous FKRP protein in the HAP1-FKRP $_{\text {KO }}$ cells whereas the signal co-localized with the Golgi markers (GM130 and TGN46 for cis- and trans-Golgi respectively) in the HAP1-WT cell line as expected (Figure 1A). The HAP1-FKRP ${ }_{\mathrm{KO}}$ cell line, while presenting normal cell growth, was characterized by small cytoplasmic volume and membrane disturbances, specifically deficiency in filipodia, as detected by membrane staining for $\beta$-integrin and Wheat Germ Agglutinin (WGA) (Figure 1B). IF and flow-cytometry analysis showed a substantial reduction of the functional $\alpha$-DG glycosylation at the cell membrane based on the IIH6 specific antibody (Figure 1C), confirming the absence of FKRP activity in HAP1-FKRP ${ }_{\mathrm{KO}}$ cells and the utility of using this cell line for FKRP mutant protein characterization.

To be able to select the exogenous FKRP positive cells in flow cytometry experiments and to directly detect the protein in cellular localization experiments without the need of antibodies, we generated a fluorescently labelled fusion protein. This protein consists of the human FKRP coding sequence fused, at its C-terminus and through a flexible linker, to a mCherry $(\mathrm{mCh})$ fluorescent reporter protein (FKRPmCh). IF staining experiments demonstrated the integrity of the fusion protein since the mCherry signal co-localized with the labelling for FKRP and with the trans-Golgi marker TGN46 (Supp. Figures S1A and S1B). In addition, only the mCherry positive cells were positive for membrane staining with the IIH6 antibody in nonpermeabilized conditions (Supp. Figure S1C), indicating that the addition of the fluorescent 
reporter did not alter the normal cellular localization and function of the WT FKRP protein and that the construct could be used further for genetic variants characterization.

\subsection{Cellular localization of FKRP mutant proteins}

With the aim of characterizing FKRP mutant proteins using our overexpression system, we chose to test seven missense patient genetic variants associated with pathologies ranging from the severe CMD to the mild LGMD2I and localized throughout the entire length of the protein (Table 1A). In addition to the patient genetic variants, two control mutants were used. In the first, the di-Arginine (R) motif at positions 2 and 5 (R2R5) responsible for the Golgi positioning was mutated to Glutamic acid (E) residues (E2E5). In the second, the catalytic residues composed of two Aspartic acids (D) and a Valine (V) in positions 362-364 (DvD) were mutated into asparagine residues $(\mathrm{N})(\mathrm{NNN})$. The first mutant protein was previously described as being unable to traffic from the ER to the Golgi, whereas the second was shown to abrogate the enzymatic activity of FKRP (Esapa et al., 2002).

When overexpressed in HAP1-FKRP ${ }_{\text {Ко }}$ cells, the different constructs presented three different profiles. The WT construct co-localized with the trans-Golgi, as well as the L276I, NM_001039885.2:p.Tyr182Cys (Y182C) and NM_001039885.2:p.Val300Ala (V300A) mutant proteins (Figure 2A). The mCherry signal of the E2E5 and NM_001039885.2:p.Val405Leu (V405L) mutants presented a cytoplasmic localization, later confirmed to co-localize with the ER marker calnexin (CNX) (Supp. Figure S2). Finally, we observed a dual ER/Golgi co-localization for the NNN, NM_001039885.2:p.Ser221Arg (S221R), NM_001039885.2:p.Pro448Leu (P448L) and NM_001039885.2:p.Ala455Asp (A455D) mutant proteins, indicating that these proteins were retained in the ER but were nevertheless able to overcome this retention. Overall, we concluded that, in our system, some 
genetic variants lead to different levels of ER-retention but that evasion from this system is possible for a number of these mutant proteins.

\subsection{Functional analysis of FKRP mutant proteins}

Given that some mutants were co-localized in the Golgi, we tested their protein level and potential for functionality by flow-cytometry using the mCherry and glycosylation signals, respectively (Supp. Figure S3). We observed that the amount of FKRPmCh protein steadily increased as in the WT for all mutants with the exception of the E2E5, V405L and A455D mutants, suggesting that the presence of the genetic variant may lead to protein instability (Figure 2B). As expected, the increase of FKRPmCh amount was associated with an increase in $\alpha$-DG functional glycosylation for the WT in the mCherry positive population. The Y182C and L276I mutants led to the same glycosylation levels than the WT, demonstrating a fully functional capacity, whereas the S221R, P448L and A455D, although displaying a slower increase, soon caught up with WT functional levels at 45h (Supp. Figure S4). The reduced level of glycosylation observed for the V405L is probably related to the low level of the protein. The NNN mutant control was functionally fully impaired as predicted since corresponding to a catalytically dead enzyme while the E2E5 mutant displayed a marked functional reduction most likely due to the impaired traffic to the Golgi compartment as demonstrated in the IF staining. Remarkably, the V300A mutant protein, which was correctly localized in the Golgi apparatus, displayed a striking reduced level of glycosylation, indicating that, although the protein is able to traffic correctly, it fails to extend the $\alpha$-DG glycosylation moiety. Taken together, our results showed that overexpression of FKRP mutant proteins in the HAP1-FKRP ${ }_{\mathrm{KO}}$ cell line can be used to study the localization and the function potential of FKRP mutant proteins. Additionally, we showed that characterization of cellular localization alone is not sufficient to infer protein function. 


\subsection{Characterization of FKRP patient genetic variants localized between residues 300} and 328

We were intrigued about the functional impairment induced by V300A, which is located at the beginning of the predicted catalytic domain (Alhamidi et al., 2011). The corresponding mutant protein did not present signs of ER-retention nor was its protein level low by flow cytometry, indicating that the protein was not identified by the QC/ERAD systems as misfolded. Yet, this protein was not able to function properly, i.e. glycosylation of $\alpha$-DG, despite the mutated residue not being localized in the DvD catalytic core residues (positions 362-364). We decided to investigate further the cellular localization and function of other genetic variants positioned downstream of the 300 Valine residue and in the beginning of the catalytic domain based on the published FKRP model (Alhamidi et al., 2011). For this purpose, we generated 14 additional patient genetic variants present between residues 300 and 328 of the FKRP protein (Table 1B). Our mutant panel included NM_001039885.2:p.Tyr307Asn (Y307N) and NM_001039885.2:p.Cys318Tyr (C318Y), previously characterized to be localized in the Golgi in other cell types (Dolatshad et al., 2005; Torelli et al., 2005). The associated phenotypes encompassed all severities, with the majority of genetic variants being reported in the Leiden Muscular Dystrophy database only one or two times.

The IF staining demonstrated that, alike the V300A mutant, all these additional FKRP mutant proteins, to the exception of the NM_001039885.2:p.Tyr328Ser (Y328S), co-localized with the Golgi apparatus (Figure 3A). Regarding protein function, all the tested genetic variants presented reduced levels of function compared with the WT (Figure 3B), with four mutants, NM_001039885.2:(p.Pro305Leu (P305L), Y307N, NM_001039885.2:p.Thr314Pro (T314P) and C318Y presenting functional levels close to the catalytically dead NNN mutant. We could 
also observe that the nature of the amino-acid modification, in addition to the amino-acid position, also impacted the function, as the same Threonine (T) residue in position 314 , when modified to a Methionine (M) was still functional where modification to a Proline (P) abrogated completely the function. The modification of the Proline (P) in position 316 to either Arginine (R), Serine (S) or Threonine (T) did not change dramatically the overall function. All these results indicated that missense mutations localized between residues 300 to 321 of the human FKRP protein, and which we refer to $\mathrm{FKRP}_{300-321}$ region, do not seem to induce ER-retention but nevertheless give rise to non-functional or severely impaired mutant proteins in our system. Moreover, four genetic variants abrogated completely the protein function, perhaps indicative of the importance of these residues for the protein activity.

\section{Discussion}

In this study, we evaluated the cellular localization, as well as the level of activity of FKRP proteins bearing genetic variants commonly found in patients using an overexpression system based on the HAP1 FKRP ${ }_{\text {KO }}$ cell line. In this model system, we identified one genetic variant, V405L, which leads to a strict ER localization. Interestingly, this change between the two aliphatic amino acids is quite conservative and is not predicted to overly disrupt the secondary structure of the protein. It is therefore possible that the consequence will pertain on the tertiary or quaternary structure or else the corresponding residue is important for association with a protein implicated in the trafficking to the Golgi. We also identified three mutant proteins, S221R, P448L and A455D, found to be retained in the ER but which were nevertheless able to overcome this retention when overexpressed. This "leakage effect" has been previously described and seen in other misfolded proteins (Gomez-Navarro \& Miller, 
2016; Kawaguchi, Hsu, \& Ng, 2010). Interestingly, these three mutants displayed normal functional levels. Additional mutants that were purely Golgi-resident presented different degrees of defect in enzymatic activity, with a few of them being enzymatically dead (P305L, Y307N, T314P and C318Y), indicating that this particular region might be important for the enzymatic activity of FKRP within the Golgi. Finally, some mutants behave similarly to the WT protein (Y182C and L276I) with respect to localization in the Golgi and glycosyltransferase function in our system.

The result obtained with the most frequent FKRP genetic variant L276I, which is well known to be associated with the mildest form of the disease, clearly pinpoints to one of the limitations of our cellular system. Here, the corresponding mutant is undistinguishable to WT whereas we previously showed that it presents a defect in glycosylation function in vivo (Gicquel et al., 2017). Clearly, the high overexpression levels, leading to the exacerbated protein escape from the ER into the Golgi, may not allow the observation of subtle differences induced by this type of genetic variants. We might postulate that the L276I, as well as the Y182C mutant protein, may require extended folding times and be less readily available for the glycosylation process in skeletal muscle context. This hypothesis is supported by the fact that the L276I mutant protein was seen to interact more strongly with CNX, a molecular chaperone of the ER, than the WT (Esapa et al., 2005).

Our data indicates that it is possible to obtain a full functionality with overexpression of proteins that are recognized as being abnormal by the QC as demonstrated by their ER localization. A recent report demonstrated the correct function of the P488L mutant protein in vivo (Tucker, Lu, Xiao, \& Lu, 2018). The authors showed that the mutant protein was able to restore the $\alpha$-DG glycosylation at the muscle membrane and correction of the dystrophic phenotype when overexpressed by adeno-associated virus (AAV) injection in a $\mathrm{P} 448 \mathrm{~L}^{\text {neo- }}$ 
mouse model. In addition, in a more recent study, the same group showed that supplementation of ribitol in drinking water of the $\mathrm{P} 448 \mathrm{~L}^{\text {neo- }}$ mouse increased $\alpha$-DG glycosylation (Cataldi, Lu, Blaeser, \& Lu, 2018), indicating that even the endogenous P448L mutant protein present in the mice might still retain some level of functionality. Altogether, these different pieces of evidence support the idea that a pharmacological strategy allowing a bypass of the QC might lead to a therapeutic benefit for patients with the corresponding genetic variants.

Our findings also revealed that patient genetic variants localized within the $\mathrm{FKRP}_{300-321}$ region of the protein, remarkably are all correctly localized in the Golgi but correspond to functionally impaired proteins in our cellular model. Their correct localization indicates that, after protein folding in the ER, the structure of these mutant proteins is possibly qualified as being correctly folded by the QC system and the proteins are allowed to proceed further towards their final destination. However, once in the Golgi, they might not have or fail to attain the necessary features for proper function. One can think of incorrect localization within the Golgi apparatus, impossibility to reach an active conformation or dimerization, or impaired interaction with the substrate, the $\alpha-\mathrm{DG}$ glycosylation growing chain or additional partners such as FKTN or Transmembrane Protein 5 (TMEM5) protein (Alhamidi et al., 2011; Nishihara et al., 2018). The family of glycosyltransferases (GTs), of which FKRP is a member, encompass enzymes responsible for the transfer of sugar moieties and the formation of glycosidic linkages (Lairson, Henrissat, Davies, \& Withers, 2008). The consensus in the field is that the nucleotide-binding residues of GTs are not restricted to the characteristic DxD motif, but can be also extended to amino-acids localized upstream and downstream of this region (Breton \& Imberty, 1999). While the $\mathrm{FKRP}_{300-321}$ area is not close to the catalytic DxD motif when the amino-acid linear sequence is considered, it is conceivable that this region is 
required for the catalytic function and participate in the catalytic pocket through the 3D conformation. Despite our attempt, no parallel between the prediction of the deleterious score by online predictors and the severity of the disease caused by the FKRP variants was noted (Supp. Table S1). Likewise, no relevant tri-dimensional model was achieved since the results obtained with different prediction softwares were inconsistent. A crystallography model of FKRP protein is then crucial for better understanding the mechanism of enzymatic activation and function and shed a light on the structural consequences arising from the mutated residues. Interestingly, to the exception of the P305L mutant which is associated to an LGMD phenotype, all the identified catalytically "dead" genetic variants are associated with severe phenotypes such as MEB/CMD, LIS and WWS. This information is in support of our findings for the severely impaired function of these mutated proteins and might indicate that a similar phenotype would be present in the human tissue context. Furthermore, patient genetic variants in FKTN, the FKRP homologous protein that shares the same substrate and activity, were described to be correctly localized in the Golgi (Tachikawa et al., 2012) while being functionally impaired, (Kanagawa et al., 2016), reinforcing the relevance of our results.

In conclusion, we propose the following scenario of fate of the different FKRP protein variants, suggesting the absence of correlation between the subcellular localization and function of the mutant proteins (Figure 4). Overall, we believe that our experimental approach, integrating the information on the mutant protein cellular localization with its function, contributes for the complete understanding of the pathogenic impact of the patient mutation and of the function of the protein. Indeed, we might have uncovered a particular region outside the catalytic motif that seems important for the enzymatic activity of FKRP within the Golgi. Unfortunately, it is difficult to make any conclusions about the severity of the disease based solely on the results obtained in our cellular model. It is highly probable that 
additional factors intervene to explain the phenotype of the variants or combinations of variants. Lastly, the demonstration that the alteration of one amino acid interfering with the proper protein folding process might nevertheless lead to a protein with functionality can lead to further studies about the potential for the rescue of such proteins from degradation as a treatment option for patients.

\section{Acknowledgments}

We would like to thank all the Progressive Muscular Dystrophies group members. We are grateful to the "Imaging and Cytometry Core Facility" of Généthon for technical support and to Genopole Research, Evry, for the purchase of the equipment. The authors have no conflict of interest to declare. 


\section{References}

Adzhubei, I. A., Schmidt, S., Peshkin, L., Ramensky, V. E., Gerasimova, A., Bork, P., .. . Sunyaev, S. R. (2010). A method and server for predicting damaging missense mutations. Nat Methods, 7(4), 248-249. doi: 10.1038/nmeth0410-248

Alhamidi, M., Kjeldsen Buvang, E., Fagerheim, T., Brox, V., Lindal, S., Van Ghelue, M., \& Nilssen, O. (2011). Fukutin-related protein resides in the Golgi cisternae of skeletal muscle fibres and forms disulfide-linked homodimers via an N-terminal interaction. PLoS One, 6(8), e22968. doi: 10.1371/journal.pone.0022968

Barresi, R., \& Campbell, K. P. (2006). Dystroglycan: from biosynthesis to pathogenesis of human disease. J Cell Sci, 119(Pt 2), 199-207.

Beltran-Valero de Bernabe, D. (2004). Mutations in the FKRP gene can cause muscle-eyebrain disease and Walker-Warburg syndrome. Journal of Medical Genetics, 41(5), e61-e61. doi: 10.1136/jmg.2003.013870

Bolte, S., \& Cordelieres, F. P. (2006). A guided tour into subcellular colocalization analysis in light microscopy. J Microsc, 224(Pt 3), 213-232. doi: 10.1111/j.13652818.2006.01706.x

Bouchet, C., Gonzales, M., Vuillaumier-Barrot, S., Devisme, L., Lebizec, C., Alanio, E., . . . Seta, N. (2007). Molecular heterogeneity in fetal forms of type II lissencephaly. Hum Mutat, 28(10), 1020-1027. doi: 10.1002/humu.20561

Breton, C., \& Imberty, A. (1999). Structure/function studies of glycosyltransferases. Curr Opin Struct Biol, 9(5), 563-571.

Brockington, M., Blake, D. J., Prandini, P., Brown, S. C., Torelli, S., Benson, M. A., . . . Muntoni, F. (2001). Mutations in the fukutin-related protein gene (FKRP) cause a form of congenital muscular dystrophy with secondary laminin alpha2 deficiency and abnormal glycosylation of alpha-dystroglycan. [Case Reports

Research Support, Non-U.S. Gov't]. Am J Hum Genet, 69(6), 1198-1209. doi: $10.1086 / 324412$

Carotti, M., Marsolier, J., Soardi, M., Bianchini, E., Gomiero, C., Fecchio, C., . . . Sandona, D. (2018). Repairing folding-defective alpha-sarcoglycan mutants by CFTR correctors, a potential therapy for limb-girdle muscular dystrophy 2D. Hum Mol Genet, 27(6), 969-984. doi: 10.1093/hmg/ddy013

Cataldi, M. P., Lu, P., Blaeser, A., \& Lu, Q. L. (2018). Ribitol restores functionally glycosylated alpha-dystroglycan and improves muscle function in dystrophic FKRPmutant mice. Nat Commun, 9(1), 3448. doi: 10.1038/s41467-018-05990-z 
Chen, X., Zaro, J. L., \& Shen, W. C. (2013). Fusion protein linkers: property, design and functionality. Adv Drug Deliv Rev, 65(10), 1357-1369. doi: 10.1016/j.addr.2012.09.039

Choi, Y., Sims, G. E., Murphy, S., Miller, J. R., \& Chan, A. P. (2012). Predicting the functional effect of amino acid substitutions and indels. PLoS One, 7(10), e46688. doi: 10.1371/journal.pone. 0046688

de Paula, F., Vieira, N., Starling, A., Yamamoto, L. U., Lima, B., de Cassia Pavanello, R., ... Zatz, M. (2003). Asymptomatic carriers for homozygous novel mutations in the FKRP gene: the other end of the spectrum. Eur J Hum Genet, 11(12), 923-930. doi: 10.1038/sj.ejhg.5201066

Dolatshad, N. F., Brockington, M., Torelli, S., Skordis, L., Wever, U., Wells, D. J., . . . Brown, S. C. (2005). Mutated fukutin-related protein (FKRP) localises as wild type in differentiated muscle cells. [Research Support, Non-U.S. Gov't]. Exp Cell Res, 309(2), 370-378. doi: 10.1016/j.yexcr.2005.06.017

Endo, Y., Dong, M., Noguchi, S., Ogawa, M., Hayashi, Y. K., Kuru, S., . . . Nishino, I. (2015). Milder forms of muscular dystrophy associated with POMGNT2 mutations. Neurol Genet, 1(4), e33. doi: 10.1212/nxg.0000000000000033

Ervasti, J. M., \& Campbell, K. P. (1993). A role for the dystrophin-glycoprotein complex as a transmembrane linker between laminin and actin. J Cell Biol, 122(4), 809-823.

Esapa, C. T., Benson, M. A., Schroder, J. E., Martin-Rendon, E., Brockington, M., Brown, S. C., . . . Blake, D. J. (2002). Functional requirements for fukutin-related protein in the Golgi apparatus. Hum Mol Genet, 11(26), 3319-3331.

Esapa, C. T., McIlhinney, R. A., \& Blake, D. J. (2005). Fukutin-related protein mutations that cause congenital muscular dystrophy result in ER-retention of the mutant protein in cultured cells. Hum Mol Genet, 14(2), 295-305. doi: 10.1093/hmg/ddi026

Gerin, I., Ury, B., Breloy, I., Bouchet-Seraphin, C., Bolsee, J., Halbout, M., . . . Bommer, G. T. (2016). ISPD produces CDP-ribitol used by FKTN and FKRP to transfer ribitol phosphate onto alpha-dystroglycan. Nat Commun, 7, 11534 . doi: 10.1038/ncomms 11534

Gicquel, E., Maizonnier, N., Foltz, S. J., Martin, W. J., Bourg, N., Svinartchouk, F., . . . Richard, I. (2017). AAV-mediated transfer of FKRP shows therapeutic efficacy in a murine model but requires control of gene expression. Hum Mol Genet, 26(10), 19521965. doi: $10.1093 / \mathrm{hmg} / \mathrm{ddx} 066$

Gomez-Navarro, N., \& Miller, E. (2016). Protein sorting at the ER-Golgi interface. J Cell Biol, 215(6), 769-778. doi: 10.1083/jcb.201610031

Guglieri, M., Straub, V., Bushby, K., \& Lochmuller, H. (2008). Limb-girdle muscular dystrophies. Curr Opin Neurol, 21(5), 576-584. doi: 10.1097/WCO.0b013e32830efdc2 
Hohenester, E., Tisi, D., Talts, J. F., \& Timpl, R. (1999). The crystal structure of a laminin Glike module reveals the molecular basis of alpha-dystroglycan binding to laminins, perlecan, and agrin. [Research Support, Non-U.S. Gov't]. Mol Cell, 4(5), 783-792.

Imae, R., Manya, H., Tsumoto, H., Osumi, K., Tanaka, T., Mizuno, M., . . . Endo, T. (2018). CDP-glycerol inhibits the synthesis of the functional O-mannosyl glycan of alphadystroglycan. J Biol Chem, 293(31), 12186-12198. doi: 10.1074/jbc.RA118.003197

Kanagawa, M., Kobayashi, K., Tajiri, M., Manya, H., Kuga, A., Yamaguchi, Y., . . Toda, T. (2016). Identification of a Post-translational Modification with Ribitol-Phosphate and Its Defect in Muscular Dystrophy. Cell Rep, 14(9), 2209-2223. doi: 10.1016/j.celrep.2016.02.017

Kawaguchi, S., Hsu, C. L., \& Ng, D. T. (2010). Interplay of substrate retention and export signals in endoplasmic reticulum quality control. PLoS One, 5(11), e15532. doi: 10.1371/journal.pone.0015532

Kefi, M., Amouri, R., Chabrak, S., Mechmeche, R., \& Hentati, F. (2008). Variable cardiac involvement in Tunisian siblings harboring FKRP gene mutations. Neuropediatrics, 39(2), 113-115. doi: 10.1055/s-2008-1081465

Keramaris-Vrantsis, E., Lu, P. J., Doran, T., Zillmer, A., Ashar, J., Esapa, C. T., . . Lu, Q. L. (2007). Fukutin-related protein localizes to the Golgi apparatus and mutations lead to mislocalization in muscle in vivo. [Research Support, Non-U.S. Gov't]. Muscle Nerve, 36(4), 455-465. doi: 10.1002/mus.20833

Lairson, L. L., Henrissat, B., Davies, G. J., \& Withers, S. G. (2008). Glycosyltransferases: structures, functions, and mechanisms. Annu Rev Biochem, 77, 521-555. doi: 10.1146/annurev.biochem.76.061005.092322

Louhichi, N., Triki, C., Quijano-Roy, S., Richard, P., Makri, S., Meziou, M., . . Fakhfakh, F. (2004). New FKRP mutations causing congenital muscular dystrophy associated with mental retardation and central nervous system abnormalities. Identification of a founder mutation in Tunisian families. Neurogenetics, 5(1), 27-34. doi: $10.1007 / \mathrm{s} 10048-003-0165-9$

Matsumoto, H., Noguchi, S., Sugie, K., Ogawa, M., Murayama, K., Hayashi, Y. K., \& Nishino, I. (2004). Subcellular localization of fukutin and fukutin-related protein in muscle cells. [Research Support, Non-U.S. Gov't]. J Biochem, 135(6), 709-712. doi: $10.1093 / \mathrm{jb} / \mathrm{mvh} 086$

Mercuri, E., Brockington, M., Straub, V., Quijano-Roy, S., Yuva, Y., Herrmann, R., ... Muntoni, F. (2003). Phenotypic spectrum associated with mutations in the fukutinrelated protein gene. Ann Neurol, 53(4), 537-542. doi: 10.1002/ana.10559

Mercuri, E., Topaloglu, H., Brockington, M., Berardinelli, A., Pichiecchio, A., Santorelli, F., . . Muntoni, F. (2006). Spectrum of brain changes in patients with congenital muscular dystrophy and FKRP gene mutations. Arch Neurol, 63(2), 251-257. doi: 10.1001/archneur.63.2.251 
Nishihara, R., Kobayashi, K., Imae, R., Tsumoto, H., Manya, H., Mizuno, M., . . . Toda, T. (2018). Cell endogenous activities of fukutin and FKRP coexist with the ribitol xylosyltransferase, TMEM5. Biochem Biophys Res Commun, 497(4), 1025-1030. doi: 10.1016/j.bbrc.2018.02.162

Quijano-Roy, S., Marti-Carrera, I., Makri, S., Mayer, M., Maugenre, S., Richard, P., . . . Carlier, R. Y. (2006). Brain MRI abnormalities in muscular dystrophy due to FKRP mutations. Brain Dev, 28(4), 232-242. doi: 10.1016/j.braindev.2005.08.003

Reva, B., Antipin, Y., \& Sander, C. (2011). Predicting the functional impact of protein mutations: application to cancer genomics. Nucleic Acids Res, 39(17), e118. doi: 10.1093/nar/gkr407

Richard, I., Laurent, J. P., Cirak, S., \& Vissing, J. (2016). 216th ENMC international workshop: Clinical readiness in FKRP related myopathies January 15-17, 2016 Naarden, The Netherlands. Neuromuscul Disord, 26(10), 717-724. doi: 10.1016/j.nmd.2016.08.012

Riemersma, M., Froese, D. S., van Tol, W., Engelke, U. F., Kopec, J., van Scherpenzeel, M., . . . Lefeber, D. J. (2015). Human ISPD Is a Cytidyltransferase Required for Dystroglycan O-Mannosylation. [Research Support, Non-U.S. Gov't]. Chem Biol, 22(12), 1643-1652. doi: 10.1016/j.chembiol.2015.10.014

Schindelin, J., Arganda-Carreras, I., Frise, E., Kaynig, V., Longair, M., Pietzsch, T., . . . Cardona, A. (2012). Fiji: an open-source platform for biological-image analysis. Nat Methods, 9(7), 676-682. doi: 10.1038/nmeth.2019

Soheili, T., Gicquel, E., Poupiot, J., N'Guyen, L., Le Roy, F., Bartoli, M., \& Richard, I. (2012). Rescue of sarcoglycan mutations by inhibition of endoplasmic reticulum quality control is associated with minimal structural modifications. Hum Mutat, 33(2), 429-439. doi: 10.1002/humu.21659

Stevens, E., Torelli, S., Feng, L., Phadke, R., Walter, M. C., Schneiderat, P., . . . Muntoni, F. (2013). Flow cytometry for the analysis of alpha-dystroglycan glycosylation in fibroblasts from patients with dystroglycanopathies. PLoS One, 8(7), e68958. doi: 10.1371/journal.pone.0068958

Tachikawa, M., Kanagawa, M., Yu, C. C., Kobayashi, K., \& Toda, T. (2012). Mislocalization of fukutin protein by disease-causing missense mutations can be rescued with treatments directed at folding amelioration. [Research Support, Non-U.S. Gov't]. $J$ Biol Chem, 287(11), 8398-8406. doi: 10.1074/jbc.M111.300905

Talts, J. F., Andac, Z., Gohring, W., Brancaccio, A., \& Timpl, R. (1999). Binding of the G domains of laminin alpha1 and alpha2 chains and perlecan to heparin, sulfatides, alpha-dystroglycan and several extracellular matrix proteins. [Research Support, NonU.S. Gov't]. EMBO J, 18(4), 863-870. doi: 10.1093/emboj/18.4.863

Tisi, D., Talts, J. F., Timpl, R., \& Hohenester, E. (2000). Structure of the C-terminal laminin G-like domain pair of the laminin alpha2 chain harbouring binding sites for alphadystroglycan and heparin. [Comparative Study 
Research Support, Non-U.S. Gov't]. EMBO J, 19(7), 1432-1440. doi: 10.1093/emboj/19.7.1432

Topaloglu, H., Brockington, M., Yuva, Y., Talim, B., Haliloglu, G., Blake, D., . . . Muntoni, F. (2003). FKRP gene mutations cause congenital muscular dystrophy, mental retardation, and cerebellar cysts. Neurology, 60(6), 988-992.

Torelli, S., Brown, S. C., Brockington, M., Dolatshad, N. F., Jimenez, C., Skordis, L., . . . Muntoni, F. (2005). Sub-cellular localisation of fukutin related protein in different cell lines and in the muscle of patients with MDC1C and LGMD2I. [Comparative Study

Research Support, Non-U.S. Gov't]. Neuromuscul Disord, 15(12), 836-843. doi: 10.1016/j.nmd.2005.09.004

Tucker, J. D., Lu, P. J., Xiao, X., \& Lu, Q. L. (2018). Overexpression of Mutant FKRP Restores Functional Glycosylation and Improves Dystrophic Phenotype in FKRP Mutant Mice. Mol Ther Nucleic Acids, 11, 216-227. doi: 10.1016/j.omtn.2018.02.008

von der Hagen, M., Kaindl, A. M., Koehler, K., Mitzscherling, P., Hausler, H. J., StoltenburgDidinger, G., \& Huebner, A. (2006). Limb girdle muscular dystrophy type 2I caused by a novel missense mutation in the FKRP gene presenting as acute virus-associated myositis in infancy. Eur J Pediatr, 165(1), 62-63. doi: 10.1007/s00431-005-1752-6

Wahbi, K., Meune, C., Hamouda el, H., Stojkovic, T., Laforet, P., Becane, H. M., . . Duboc, D. (2008). Cardiac assessment of limb-girdle muscular dystrophy 2I patients: an echography, Holter ECG and magnetic resonance imaging study. Neuromuscul Disord, 18(8), 650-655. doi: 10.1016/j.nmd.2008.06.365

Walter, M. C., Petersen, J. A., Stucka, R., Fischer, D., Schroder, R., Vorgerd, M., . . . Lochmuller, H. (2004). FKRP (826C $>$ A) frequently causes limb-girdle muscular dystrophy in German patients. J Med Genet, 41(4), e50.

Yamamoto, L. U., Velloso, F. J., Lima, B. L., Fogaca, L. L., de Paula, F., Vieira, N. M., .. . Vainzof, M. (2008). Muscle protein alterations in LGMD2I patients with different mutations in the Fukutin-related protein gene. J Histochem Cytochem, 56(11), 9951001. doi: $10.1369 /$ jhc.2008.951772 


\section{Figure legends}

Figure 1. Cellular characterization of HAP1 WT and HAP1 FKRP-KO cell lines. (A) Cellular morphology and endogenous FKRP cellular localization. Endogenous FKRP protein was detected in HAP1 WT cells (top panels), where the signal co-localized with the cis-Golgi Marker GM130 and the trans-Golgi marker TGN46, and was absent at these locations in HAP1 FKRP ${ }_{\mathrm{KO}}$ cells (bottom panels). Nuclei are labelled by DAPI staining. Scale bars: $30 \mu \mathrm{m}$ (bright-field), $10 \mu \mathrm{m}$ (fluorescence). (B) Small cytoplasmic volume and perturbed membrane morphology in HAP1 FKRP KO cells was observed compared to the HAP1 WT control cell line, based on the IF against membrane $\beta$-integrin and WGA. Image magnifications are presented in the right panels. Nuclei are labelled by DAPI staining. Scale bars: $20 \mu \mathrm{m}$ and $10 \mu \mathrm{m}$ for zooms (C) Characterization of $\alpha$-DG functional glycosylation in the two cell lines. The specific glycosylation, detected through the IIH6 antibody, was present in HAP1 WT but not in HAP1 FKRP KO as observed by confocal imaging. (D) Flow cytometry quantification of $\alpha$-DG functional glycosylation of HAP1-WT and HAP1 FKRP KO labelled with secondary antibody alone (II) or in combination with IIH6 primary antibody against $\alpha$-DG functional glycosylation (I + II). ****p $\leq 0.0001$.

\section{Figure 2. Cellular localization and functional characterization of FKRP mutant proteins}

in HAP1 FKRP KO cells. (A) FKRPmCh mutant proteins cellular localization after IF for the trans-Golgi compartment (TGN46). Nuclei are labelled by DAPI staining. Scale bar: $5 \mu \mathrm{m}$. (B) Functional characterization of FKRP mutant proteins through detection of $\alpha$-DG functional glycosylation after lentivirus transduction in HAP1 FKRP KO cells. In this condition, the low copy number achieved allows observation along time. The levels of the specific $\alpha$-DG glycosylation, as well as the levels of mCherry signal as a measure of 
FKRPmCh protein production, were followed and quantified through time. The levels of glycosylation were assessed only for the mCherry positive population representing the successfully transfected cells. Data is presented as the integrated Mean Fluorescence Intensity $(\mathrm{iMFI}=$ MFI $* \%$ positive cells) values in arbitrary units (A.U.) within this mCherry population.

Figure 3. Cellular localization and functional characterization of FKRP proteins with missense mutations localized between residue 300 and 328. (A) FKRPmCh mutant proteins cellular localization by IF for the trans-Golgi compartment (TGN46) after transfection in HAP1 FKRP KO cells. The mCherry signal of the fusion proteins specifically co-localized with the trans-Golgi for FKRP WT and all the mutants within residue 300 and 321. Mutant Y328S displayed a trans-Golgi co-localization as well as a cytoplasmic signal corresponding to the ER. Nuclei are labelled by DAPI staining. Scale bar: $5 \mu \mathrm{m}$. (B) Functional characterization of FKRP mutant proteins through detection of $\alpha$-DG functional glycosylation after transfection in HAP1 FKRP KO cells. The levels of glycosylation were assessed only for the mCherry positive population representing the successfully transfected cells. The functional level of the catalytically dead NNN mutant protein is represented as a dashed line. Data is presented as relative iMFI (MFI * \% positive cells) values in arbitrary units (A.U.). ns $=$ non-significant, ${ }^{*} \mathrm{p} \leq 0.05, * * \mathrm{p} \leq 0.01, * * * \mathrm{p} \leq 0.001, * * * * \mathrm{p} \leq 0.0001$.

Figure 4. Graphic model depicting proposed steps and final outcomes of normal and abnormal FKRP protein folding/function in physiological conditions in vivo. (A) Normal physiological condition. 1) FKRP is correctly folded in the ER; 2) FKRP is trafficked to the trans-Golgi; 3) FKRP transfers Rbo-5P to $\alpha$-DG glycosylation chain; 4) $\alpha$-DG is functionally glycosylated at the membrane; 5) Correct ECM binding ensures sarcolemma integrity. (B) Patient with missense mutation in FKRP- protein is retained in the ER. 1) Mutation in FKRP 
lead to ER-retained misfolded protein; 2) FKRP protein is not able to traffic correctly to the Golgi; 3) The $\alpha$-DG glycosylation chain is not extended; 4) Defects in ECM binding lead to membrane fragility and muscle dystrophy. (C) Patient with missense mutation in FKRPprotein is not functionally active. 1) FKRP is correctly folded in the ER; 2) FKRP is trafficked to the trans-Golgi; 3) FKRP does not achieve functional conformation in the Golgi and fails to transfers Rbo-5P to $\alpha$-DG glycosylation chain; 4) The $\alpha$-DG glycosylation chain is not extended; 5) Defects in ECM binding lead to membrane fragility and muscle dystrophy. 
Table 1. Description of the studied FKRP patient variants. The information presented includes the associated pathology, number of case reports and the corresponding references (Leiden Muscular Dystrophy pages; www.dmd.n1/). (A) FKRP missense mutants used in the subcellular localization and functional studies. (B) FKRP missense mutations localized between protein residues 300 and 328. The human FKRP gene (Gene ID: 79147, NM_001039885.2, CCDS12691.1) is used and gene variants are described using HGVSnomenclature (http://varnomen.hgvs.org). $\mathrm{CMD}=$ Congenital Muscular Dystrophy, MEB = Muscle-Eye-Brain disease, WWS = Walker-Warburg Syndrome, LIS = Lissencephaly, LGMD2I = Limb-Girdle Muscular Dystrophy type 2I.

A.

\begin{tabular}{|c|c|c|c|}
\hline Human genetic variants & Pathology $\dagger$ & \# Reports $\dagger$ & References \\
\hline $\begin{array}{c}\text { NM_001039885.2:c.545A }>\mathrm{G} \\
\text { NM_001039885.2:p.Tyr182Cys } \\
\text { (Y182C) }\end{array}$ & LGMD2I & 6 & $\begin{array}{l}\text { (de Paula et al., 2003; Wahbi } \\
\text { et al., 2008; Yamamoto et al., } \\
\text { 2008) }\end{array}$ \\
\hline $\begin{array}{c}\text { NM_001039885.2:c.663C }>\text { A } \\
\text { NM_001039885.2:p.Ser221Arg } \\
\text { (S221R) }\end{array}$ & CMD & 2 & $\begin{array}{l}\text { (Mercuri et al., 2006; } \\
\text { Topaloglu et al., 2003) }\end{array}$ \\
\hline $\begin{array}{c}\text { NM_001039885.2:c.826C }>\text { A } \\
\text { NM_001039885.2:p.Leu276Ile } \\
\text { (L276I) }\end{array}$ & LGMD2I & 240 & Several reports \\
\hline $\begin{array}{c}\text { NM_001039885.2:c.899T }>C \\
\text { NM_001039885.2:p.Val300Ala } \\
\text { (V300A) }\end{array}$ & LGMD2I & 5 & $\begin{array}{l}\text { (de Paula et al., 2003; Walter } \\
\text { et al., 2004; Yamamoto et al., } \\
\text { 2008) }\end{array}$ \\
\hline $\begin{array}{c}\text { NM_001039885.2:c.1213G>T } \\
\text { NM_001039885.2:p.Val405Leu } \\
\text { (V405L) }\end{array}$ & CMD & 1 & (Louhichi et al., 2004) \\
\hline $\begin{array}{c}\text { NM_001039885.2:c.1343C }>\text { T } \\
\text { NM_001039885.2:p.Pro448Leu } \\
\text { (P448L) }\end{array}$ & CMD & 3 & $\begin{array}{l}\text { (Brockington et al., 2001; } \\
\text { Dolatshad et al., 2005; } \\
\text { Mercuri et al., 2003) } \\
\end{array}$ \\
\hline $\begin{array}{c}\text { NM_001039885.2:c.1364C }>\text { A } \\
\text { NM_001039885.2:p.Ala455Asp } \\
\text { (A455D) }\end{array}$ & LGMD2I/CMD & 14 & $\begin{array}{l}\text { (Louhichi et al., 2004) (Kefi, } \\
\text { Amouri, Chabrak, } \\
\text { Mechmeche, \& Hentati, 2008; }\end{array}$ \\
\hline
\end{tabular}


B.

\begin{tabular}{|c|c|c|c|}
\hline Human genetic variants & Pathology $\dagger$ & \# Reports $\dagger$ & References \\
\hline $\begin{array}{c}\text { NM_001039885.2:c.914C >T } \\
\text { NM_001039885.2:p.Pro305Leu } \\
\text { (P305L) }\end{array}$ & LGMD2I & - & 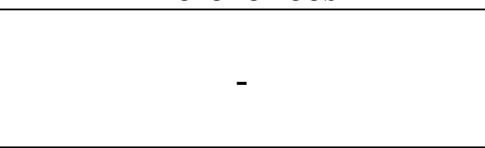 \\
\hline $\begin{array}{c}\text { NM_001039885.2:c.919T }>A \\
\text { NM_001039885.2:p.Tyr307Asn } \\
(Y 307 N)\end{array}$ & $\mathrm{MEB} / \mathrm{CMD}$ & 10 & $\begin{array}{l}\text { (Beltran-Valero de Bernabe, } \\
\text { 2004) (Mercuri et al., 2006; } \\
\text { Torelli et al., 2005) (Wahbi et }\end{array}$ \\
\hline $\begin{array}{c}\text { NM_001039885.2:c.926A }>\mathrm{G} \\
\text { NM_001039885.2:p.Tyr309Cys } \\
\text { (Y309C) }\end{array}$ & - & 1 & $\begin{array}{l}\text { (Brockington et al., 2001; } \\
\text { Mercuri et al., 2003; Torelli et } \\
\text { al., 2005) }\end{array}$ \\
\hline $\begin{array}{c}\text { NM_001039885.2:c.934C>T } \\
\text { NM_001039885.2:p.Arg312Cys } \\
\text { (R312C) }\end{array}$ & - & 1 & (Brockington et al., 2001) \\
\hline $\begin{array}{c}\text { NM_001039885.2:c.941C>T } \\
\text { NM_001039885.2:p.Thr314Met } \\
\text { (T314M) }\end{array}$ & CMD/LGMD2I & 6 & - \\
\hline $\begin{array}{c}\text { NM_001039885.2:c.940A }>C \\
\text { NM_001039885.2:p.Thr314Pro } \\
\text { (T314P) }\end{array}$ & LIS & 2 & (Bouchet et al., 2007) \\
\hline $\begin{array}{c}\text { NM_001039885.2:c.946C }>\mathrm{A} \\
\text { NM_001039885.2:p.Pro316Thr } \\
\text { (P316T) }\end{array}$ & CMD/LGMD2I & 4 & $\begin{array}{l}\text { (Mercuri et al., 2006; } \\
\text { Topaloglu et al., 2003) }\end{array}$ \\
\hline $\begin{array}{c}\text { NM_001039885.2:c.946C }>\mathrm{T} \\
\text { NM_001039885.2:p.Pro316Ser } \\
\text { (P316S) }\end{array}$ & - & 1 & (Mercuri et al., 2003) \\
\hline $\begin{array}{c}\text { NM_001039885.2:c.947C }>\mathrm{G} \\
\text { NM_001039885.2:p.Pro316Arg } \\
\text { (P316R) }\end{array}$ & CMD/LGMD2I & 3 & $\begin{array}{l}\text { (Brockington et al., 2001; } \\
\text { Quijano-Roy et al., 2006) }\end{array}$ \\
\hline $\begin{array}{c}\text { NM_001039885.2:c.953G>A } \\
\text { NM_001039885.2:p.Cys318Tyr } \\
\text { (C318Y) }\end{array}$ & WWS & 2 & $\begin{array}{l}\text { (Beltran-Valero de Bernabe, } \\
\text { 2004) (Mercuri et al., 2006) }\end{array}$ \\
\hline $\begin{array}{c}\text { NM_001039885.2:c.956T }>\mathrm{G} \\
\text { NM_001039885.2:p.Leu319Arg } \\
\text { (L319R) }\end{array}$ & LGMD2I & 1 & $\begin{array}{l}\text { (Guglieri, Straub, Bushby, \& } \\
\text { Lochmuller, 2008) }\end{array}$ \\
\hline $\begin{array}{c}\text { NM_001039885.2:c.962C }>\text { A } \\
\text { NM_001039885.2:p.Ala321Glu } \\
\text { (A321E) }\end{array}$ & LGMD2I & 1 & (von der Hagen et al., 2006) \\
\hline $\begin{array}{c}\text { NM_001039885.2:c. 983A>C } \\
\text { NM_001039885.2:p.Tyr328Ser } \\
\text { (Y328S) }\end{array}$ & CMD/LGMD2I & 2 & $\begin{array}{l}\text { (Brockington et al., 2001; } \\
\text { Quijano-Roy et al., 2006; } \\
\text { Wahbi et al., 2008) }\end{array}$ \\
\hline
\end{tabular}




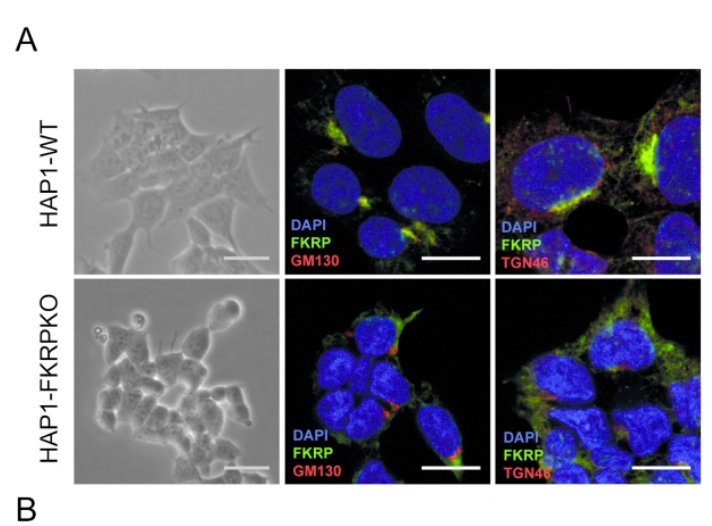

B
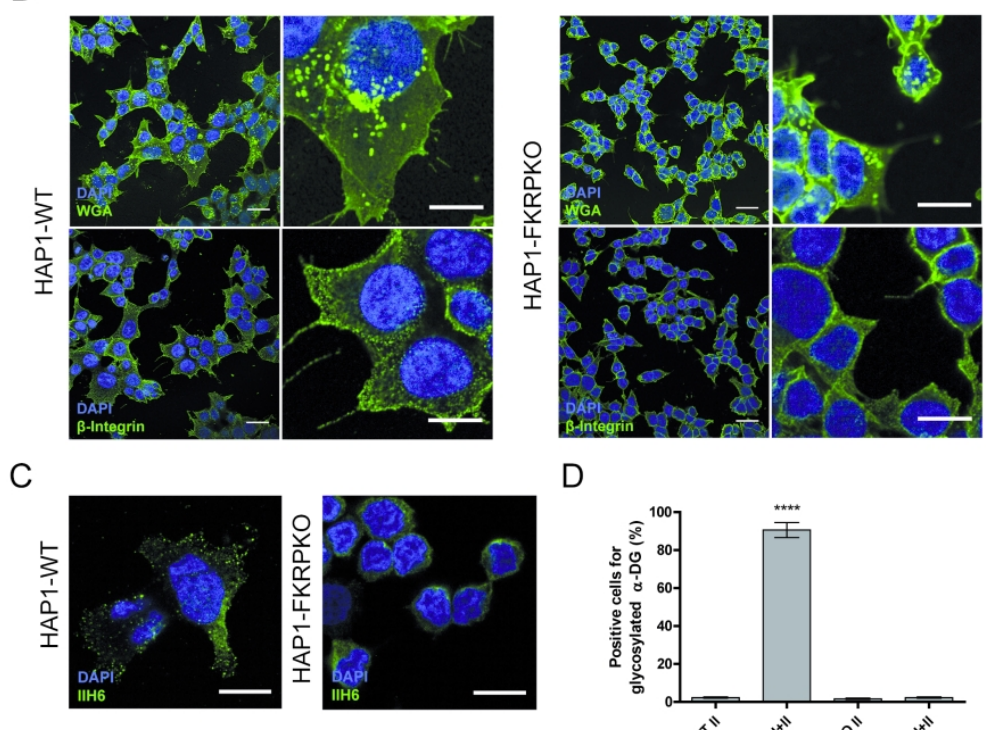

D

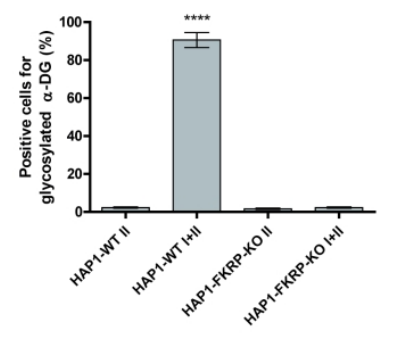

Figure 1

$210 \times 297 \mathrm{~mm}(300 \times 300 \mathrm{DPI})$ 


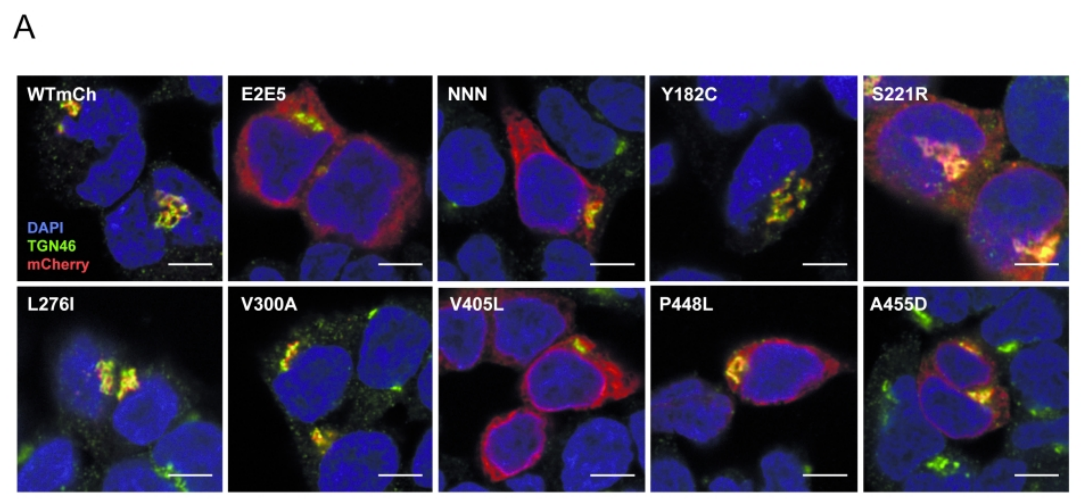

B
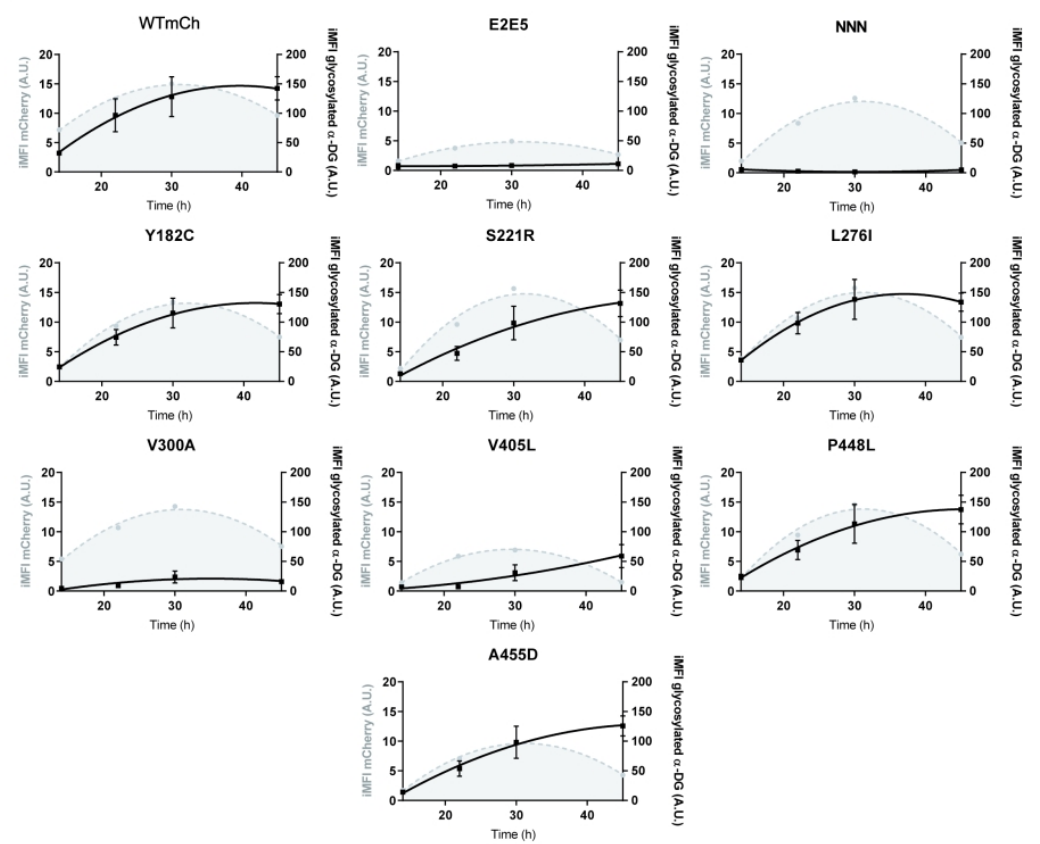

Figure 2

$210 \times 297 \mathrm{~mm}(300 \times 300 \mathrm{DPI})$ 


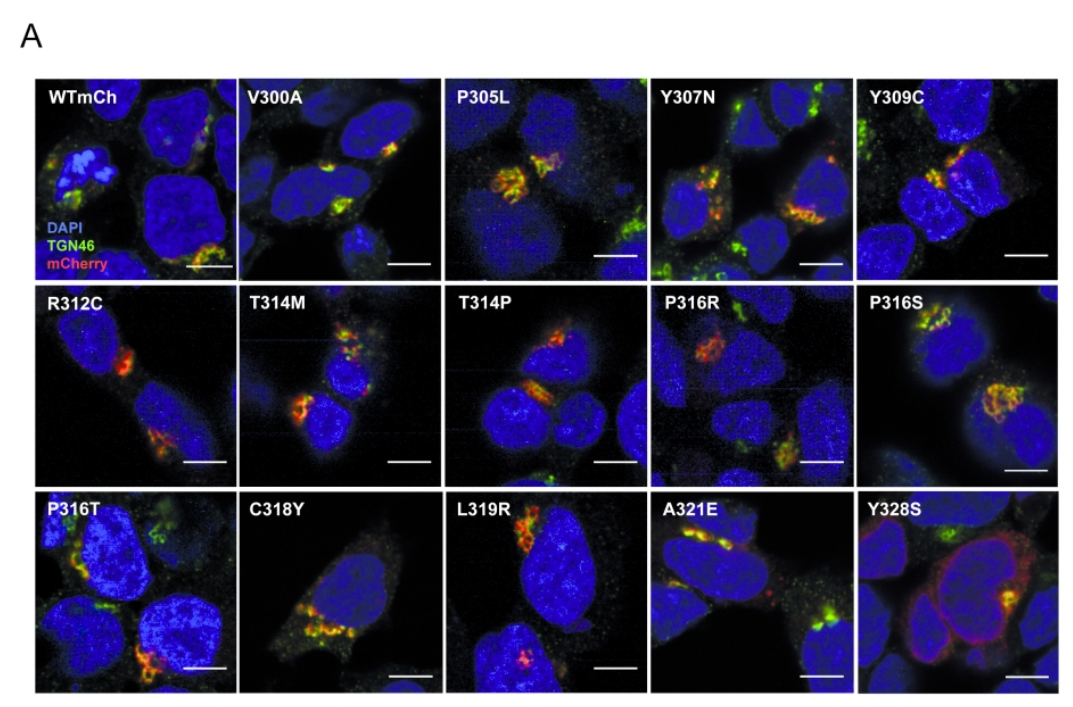

B

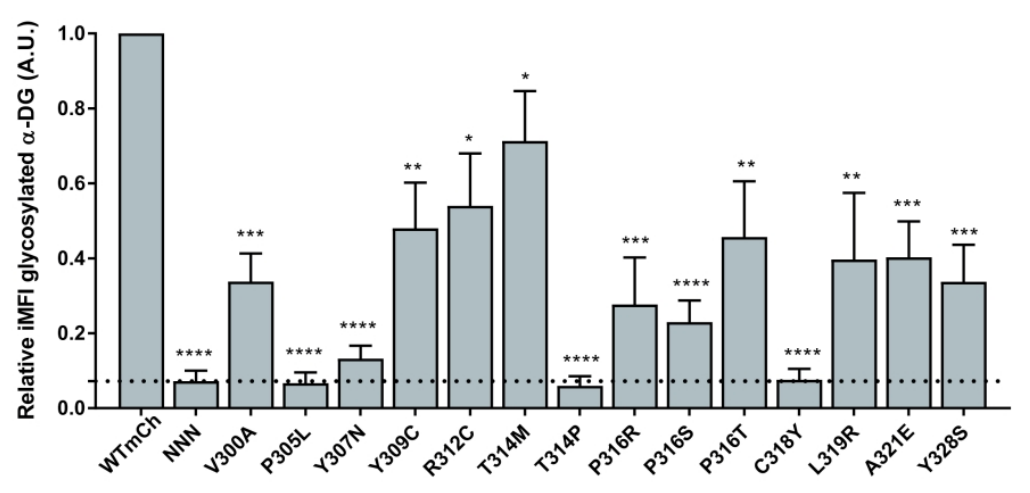

Figure 3

$210 \times 297 \mathrm{~mm}(300 \times 300 \mathrm{DPI})$ 
Patient with missense mutation in FKRP

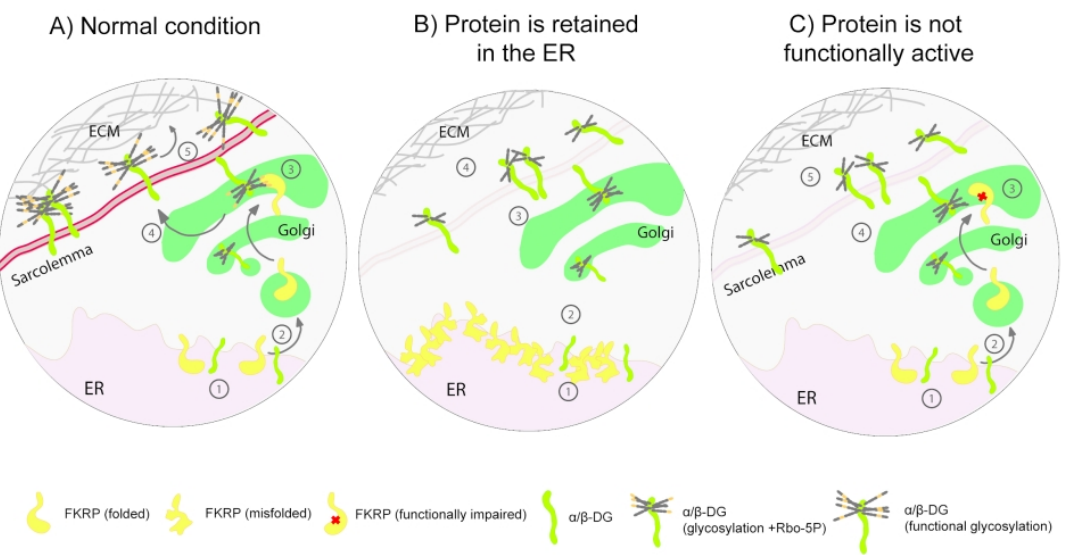

Figure 4

$210 \times 297 \mathrm{~mm}(300 \times 300$ DPI $)$ 
A


B
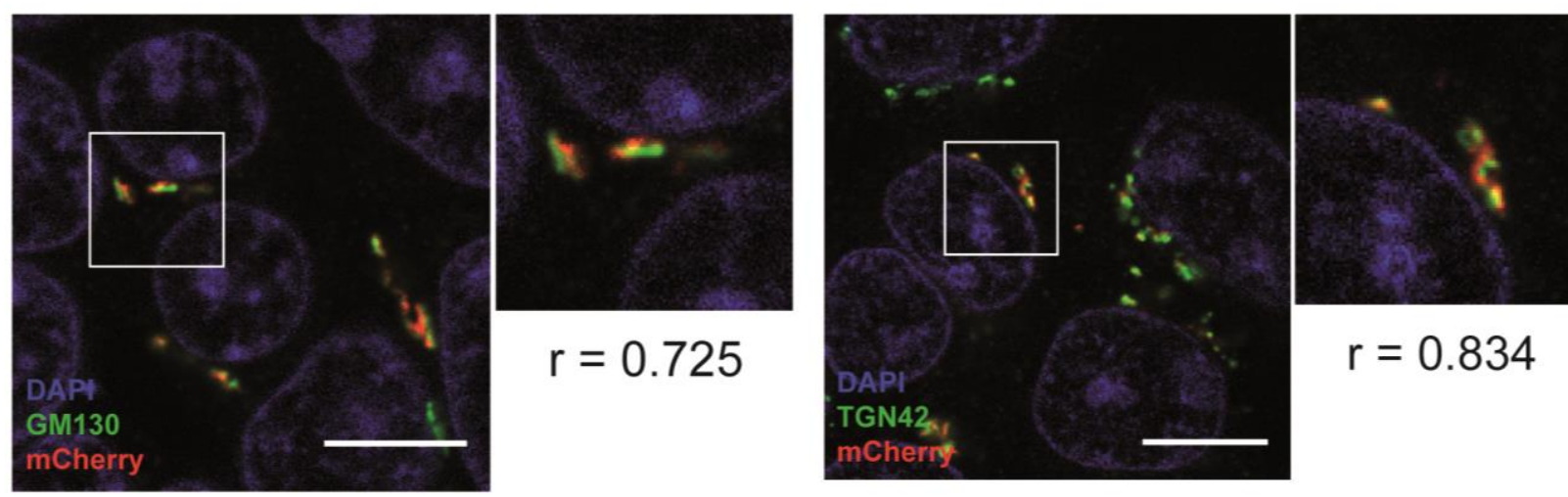

C

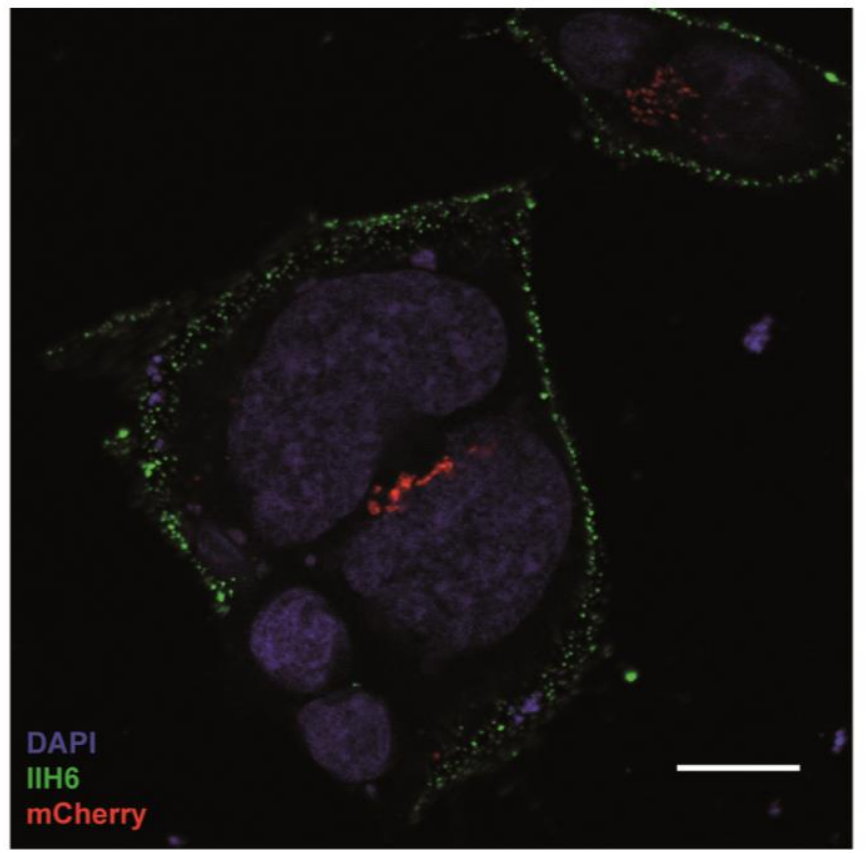

Supp. Figure 1. Characterization of the FKRPmCh fusion protein. 
(A) Correct co-localization of the mCherry signal in the FKRPmCh protein and FKRP labelling confirms the integrity of the fusion protein. Nuclei are labelled by DAPI staining. Scale bar: $5 \mu \mathrm{m}$. (B) Co-localization of the mCherry signal in the FKRPmCh protein with the cis- (GM130) and trans-Golgi (TGN46) labelling confirming that the addition of the mCherry fluorescent reporter did not interfere with the normal FKRP protein traffic. Pearson correlation coefficients between the red (mCh) and green (GM130/TGN46) calculated using the JACoP plugin for ImageJ are presented for the magnified images. Nuclei are labelled by DAPI staining. Scale bar: $10 \mu \mathrm{m}$. (C) Confocal imaging after labelling of $\alpha$-DG functional glycosylation (IIH6) in non-permeabilized conditions and transfection of FKRPmCh-WT in HAP1 FKRP KO cells. Nuclei are labelled by DAPI staining. Scale bar: $10 \mu \mathrm{m}$. 

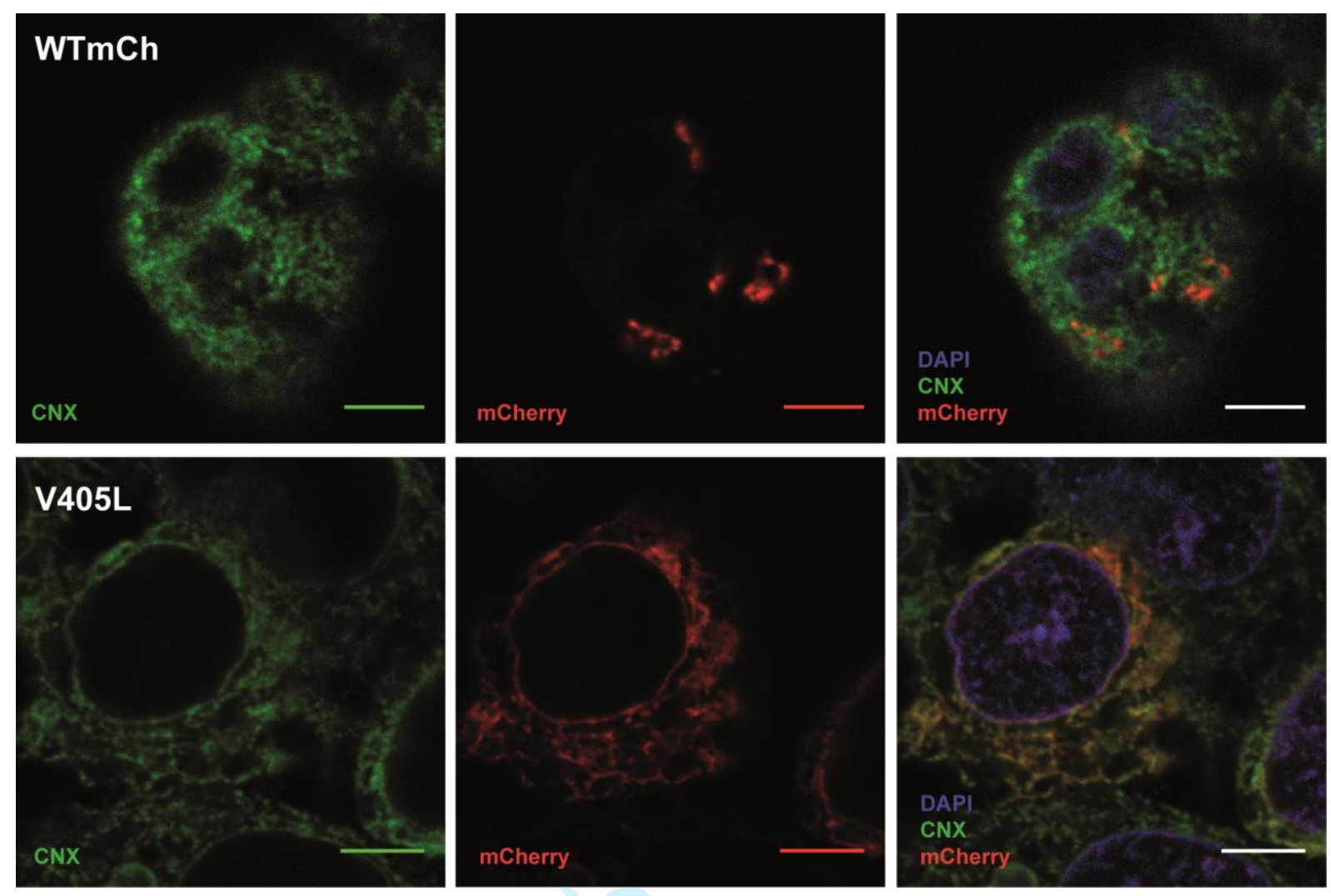

\section{Supp. Figure 2. ER-retention of FKRP mutant proteins.}

FKRPmCh WT and V405L mutant protein cellular localization after IF staining for the ER compartment (CNX). The mCherry signal of the fusion proteins specifically co-localized with the ER for FKRP V405L, as an example, confirming that the cytoplasmic signals observed represents ER-retained mutant proteins. Nuclei are labelled by DAPI staining. Scale bar: $10 \mu \mathrm{m}$. 

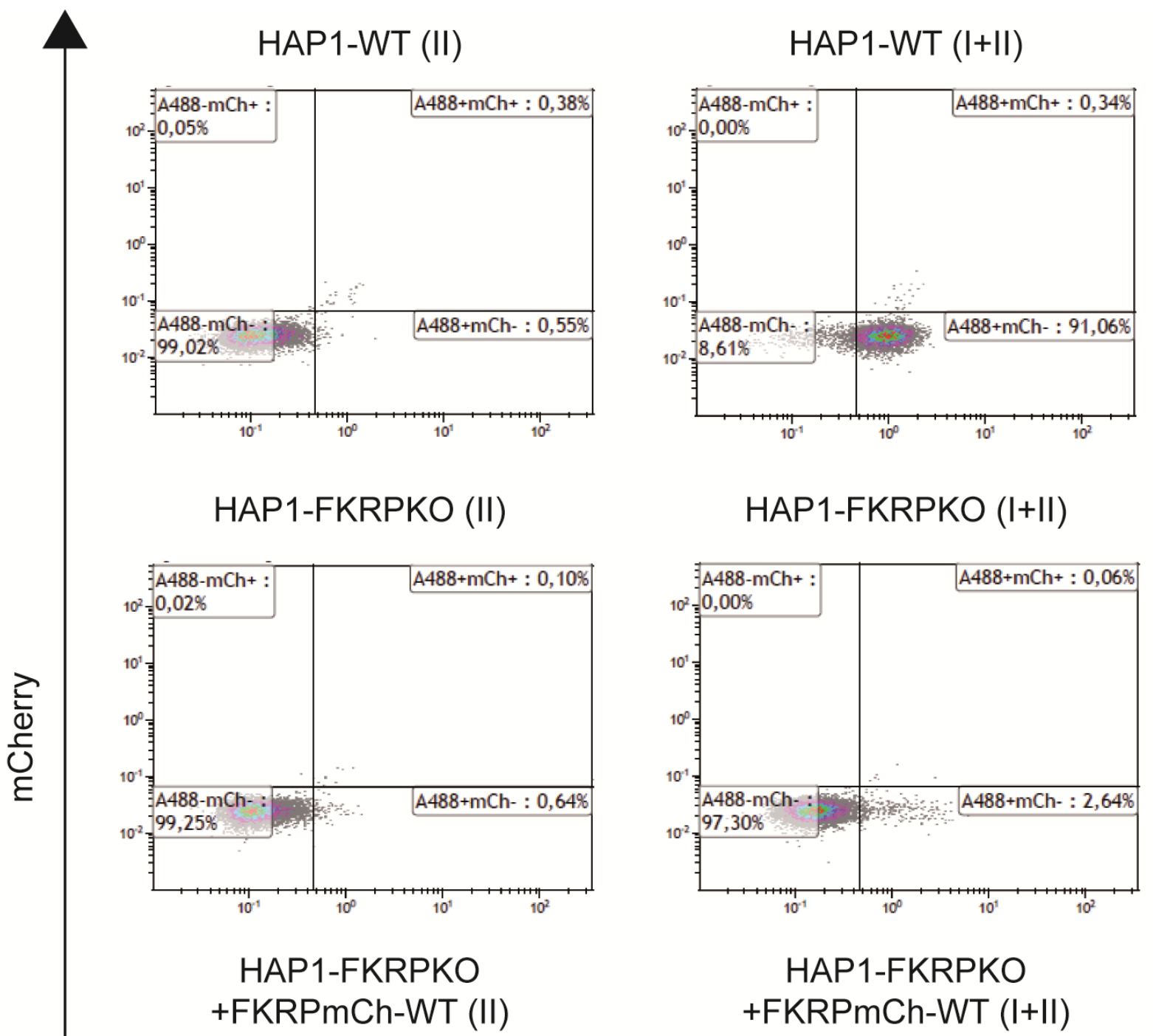
+FKRPmCh-WT (I+II)
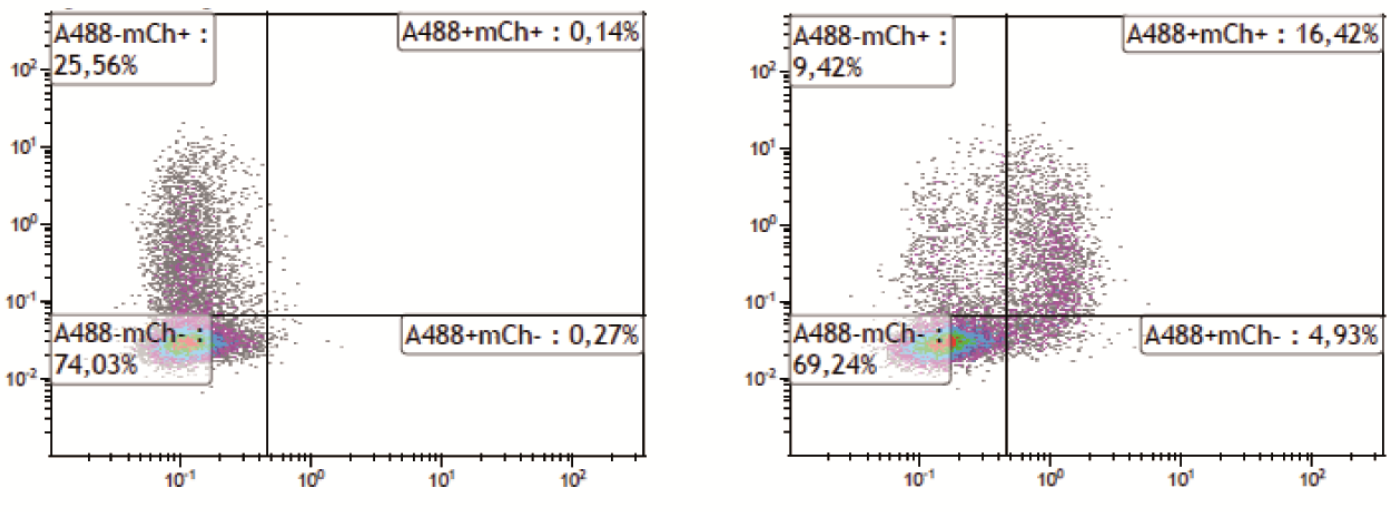

A488

Supp. Figure 3. Flow cytometry data and gates in HAP1-WT and HAP1 FKRP KO cells. 
Flow cytometry data of HAP1-WT, HAP1 FKRP KO and HAP1 FKRP KO cells transfected with FKRPmCh WT construct labelled with A488 secondary antibody alone (II) or in combination with IIH6 primary antibody against $\alpha$-DG functional glycosylation (I + II). Cell gates were defined using the appropriate experimental controls. mCherry (mCh) and A488 signal intensities are shown in axis. The data shows that the intensity of labelling (A488) of the FKRPmCh WT transfected HAP1 FKRP KO cells are in the range of the levels of intensity seen in the HAP1 WT cells (HAP1 WT I+II). 


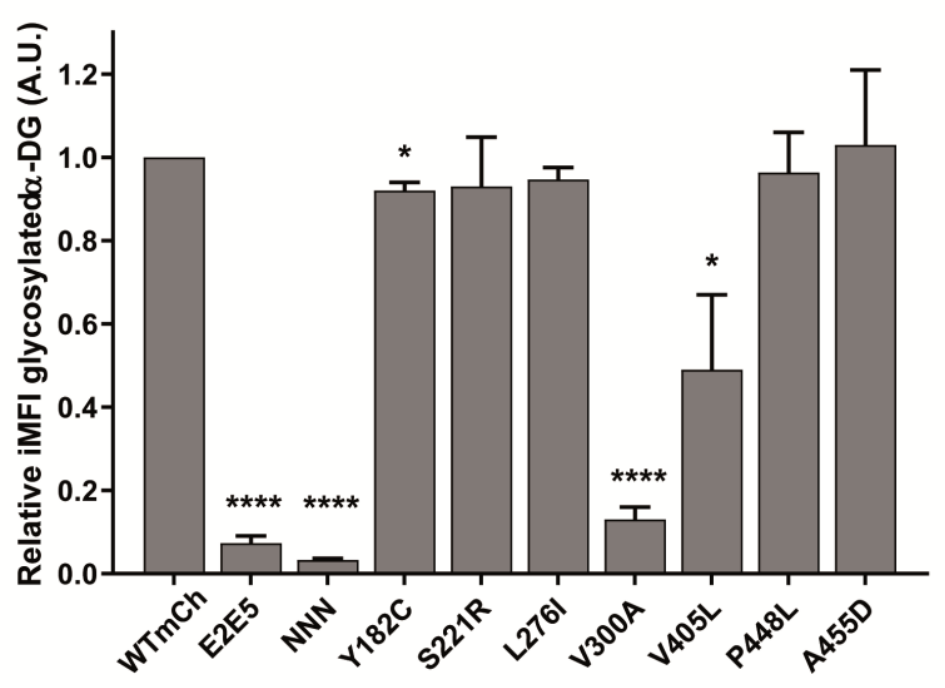

\section{Supp. Figure 4. Function of FKRP mutant proteins at 45h of expression.}

Functional characterization of FKRP mutant proteins through detection of $\alpha$-DG functional glycosylation. Only functional levels at $45 \mathrm{~h}$ are depicted confirming that the mutant proteins, E2E5, V300A and V405L, display levels comparable to the catalytically dead NNN mutant protein. The levels of glycosylation were assessed only for the mCherry positive population representing the successfully transfected cells. Data is presented as relative iMFI (MFI *\% positive cells) values in arbitrary units (A.U.). ns $=$ non-significant, $* \mathrm{p} \leq 0.05, * * \mathrm{p} \leq 0.01, * * * \mathrm{p}$ $\leq 0.001, * * * * \mathrm{p} \leq 0.0001$. 


\begin{tabular}{|l|l|lr|lr|}
\cline { 2 - 6 } \multicolumn{1}{c|}{} & \multicolumn{2}{c|}{ PolyPhen-2 } & \multicolumn{2}{c|}{ PROVEAN } & \multicolumn{2}{c|}{ MutationAssessor } \\
\hline Y182C & Prediction & Prediction & Score & Func. Impact & FI score \\
S221R & Probably damaging & Deleterious & -4.767 & Low & 1.385 \\
L276I & Possibly damaging & Neutral & -2.367 & Low & 1.445 \\
V300A & Possibly damaging & Deleterious & -0.849 & Low & 1.355 \\
V405L & Probably damaging & Neutral & -2.372 & Low & 1.87 \\
P448L & Probably damaging & Deleterious & -8.165 & Medium & 2.35 \\
A455D & Probably damaging & Deleterious & -3.969 & Medium & 2.465 \\
P305L & Probably damaging & Deleterious & -8.796 & Medium & 2.005 \\
Y307N & Probably damaging & Deleterious & -7.733 & Medium & 2.02 \\
Y309C & Probably damaging & Deleterious & -6.507 & Low & 2.02 \\
R312C & Probably damaging & Deleterious & -5.987 & Low & 1.87 \\
T314M & Probably damaging & Deleterious & -4.744 & Medium & 1.73 \\
T314P & Probably damaging & Deleterious & -5.211 & Medium & 2.455 \\
P316T & Probably damaging & Deleterious & -6.404 & Medium & 3.005 \\
P316S & Probably damaging & Deleterious & -6.404 & Medium & 3.035 \\
P316R & Probably damaging & Deleterious & -7.533 & Medium & 2.035 \\
C318Y & Probably damaging & Deleterious & -9.426 & Medium & 3.14 \\
L319R & Probably damaging & Deleterious & -4.198 & Medium & 2.51 \\
A321E & Probably damaging & Neutral & -1.115 & Low & 1.91 \\
Y328S & Possibly damaging & Deleterious & -3.526 & Low & 1.925 \\
\hline
\end{tabular}

Supp. Table 1. Prediction scores of deleteriousness for FKRP protein variants. The prediction scores of three independent online predictors (PolyPhen-2, PROVEAN and MutationAssessor) are presented for the human FKRP protein with the introduced specific variants. 


\title{
Functional and cellular localization diversity associated with
}

\section{Fukutin related protein patient genetic variants}

\author{
Sara F. Henriques ${ }^{1}$, Evelyne Gicquel ${ }^{1}$, Justine Marsolier $^{1}$ and Isabelle Richard ${ }^{1}$ \\ 1 INTEGRARE Research Unit, UMR951, Généthon, INSERM, Université Evry Val \\ d’Essonne, Université Paris-Saclay, 91002, Evry, France
}

\section{Funding information}

Généthon is part of the Biotherapies Institute for Rare Diseases (BIRD) which is supported by the Association Française contre les Myopathies (AFM-Téléthon). SH was supported by a $\mathrm{PhD}$ fellowship from the University of Paris-Saclay. 


\begin{abstract}
Genetic variants in Fukutin related protein (FKRP), an essential enzyme of the glycosylation pathway of $\alpha$-dystroglycan, can lead to pathologies with different severities affecting the eye, brain and muscle tissues. Here, we generate an in vitro cellular system to characterize the cellular localization as well as the functional potential of the most common FKRP patient missense mutations. We observe a differential retention in the Endoplasmic Reticulum (ER), indication of misfolded proteins. We find data supporting determine that mutant proteins able to overcome this ER-retention through overexpression present functional levels comparable to the wild-type. We also identify a specific region in FKRP protein localized between residues 300 and 321 in which genetic variants found in patients lead to correctly localized proteins but which are nevertheless functionally impaired or catalytically dead in our model, indicating that this particular region is-might be important for the enzymatic activity of FKRP within the Golgi. Our system thus allows the functional testing of patient specific mutant proteins and the identification of candidate mutants to be further explored with the aim of finding pharmacological treatments targeting the protein quality control system.
\end{abstract}

\title{
Keywords
}

FKRP; LGMD2I; dystroglycan; genetic variants; missense mutations; protein quality control; glycosylation. 


\section{Introduction}

Muscular dystrophies are a group of monogenic diseases affecting the skeletal muscle and characterized by a progressive loss of the muscle mass. One substantial group of muscle dystrophies termed "dystroglycanopathies" encompasses different genetic pathologies, ultimately characterized by hypoglycosylation of the protein $\alpha$-dystroglycan ( $\alpha$-DG). This protein is a fundamental component of the dystrophin-associated glycoprotein complex (DGC) in the muscles and also plays additional important roles in other tissues such as the eye and brain. Through a complex and specific glycosylation of the protein, raising its weight from 70 to $156 \mathrm{kDa}$ in muscle (Barresi \& Campbell, 2006), the plasma membrane is anchored to different extracellular-matrix (ECM) components (Hohenester, Tisi, Talts, \& Timpl, 1999; Talts, Andac, Gohring, Brancaccio, \& Timpl, 1999; Tisi, Talts, Timpl, \& Hohenester, 2000), such as laminin in the cardiac and skeletal muscles (Ervasti \& Campbell, 1993). The connexion of the fibers to the ECM is crucial for membrane stabilization, especially during muscle contraction/relaxation cycles. In dystroglycanopathies, hypoglycosylation of $\alpha$-DG leads to disruption of plasma membrane attachment, to fragility of the tissue and therefore to a dystrophic process.

The genetic basis of dystroglycanopathies is very heterogeneous, reflecting the peculiar machinery of enzymes contributing to the glycosylation of $\alpha$-DG. At present, genetic variants in 17 different genes coding for enzymes of the $\alpha$-DG glycosylation pathway have been identified as being implicated in these disorders, which range from the severe WalkerWarburg Syndrome (WWS), Muscle-Eye-Brain disease (MEB) or Congenital Muscular Dystrophy (CMD) to the mildest Limb-Girdle Muscular Dystrophies (LGMDs). 
Genetic variants in the gene coding for Fukutin-related protein (FKRP) (FKRP; MIM\# 606596), one of the enzymes of the $\alpha$-DG glycosylation pathway, can lead to all the aforementioned pathologies (MIM\# 613153, 606612, 607155) (Beltran-Valero de Bernabe, 2004; Brockington et al., 2001; Richard, Laurent, Cirak, \& Vissing, 2016). FKRP protein is a type II transmembrane protein localized in the mid/trans-Golgi apparatus of the skeletal muscle cells (Alhamidi et al., 2011). It is characterized by a short cytoplasmic domain followed by transmembrane, stem and catalytic domains, the last one possessing a DxD amino-acid motif critical for the catalytic function of the protein (Esapa et al., 2002). FKRP was described as a transferase of ribitol-phosphate into the growing glycosylation chain using as substrate the precursor molecule CDP-ribitol, and acting in succession to another related enzyme of the pathway, Fukutin (FKTN) (FKTN; MIM\# 607440) (Gerin et al., 2016; Kanagawa et al., 2016). Of note, FKRP and FKTN were recently shown to act also as a CDPglycerol transferases, which inhibits the functional glycosylation of $\alpha$-DG (Imae et al., 2018).

The most common types of FKRP patient genetic variants are missense mutations, with, in particular, a high prevalence of a specific genetic variant, the NM 001039885.2:p.Leu276Ile (L276I) (Richard et al., 2016). Missense mutations, resulting in an amino-acid change, can lead to protein folding defects when the amino-acid properties are not preserved. These misfolded proteins can be detected and blocked by the quality control (QC) system of the cells and, specifically in the case of transmembrane and secretory proteins, be retained in the Endoplasmic reticulum (ER) and directed to premature degradation by the proteasome through the ER-associated degradation (ERAD) system. Interestingly, despite the presence of the genetic variant, a certain degree of biological activity of the protein can still be preserved, suggesting that "rescue" of these proteins from the strict QC surveillance and degradation systems could ameliorate the related pathology. Indeed, pharmacological treatments proved 
successful in vitro for the rescue of FKTN (Tachikawa, Kanagawa, Yu, Kobayashi, \& Toda, 2012) or of other mutated proteins of the DGC such as the sarcoglycans (Carotti et al., 2018; Soheili et al., 2012). Some of the most prevalent FKRP missense mutations have been described to be retained in the ER (Esapa et al., 2002; Esapa, McIlhinney, \& Blake, 2005; Keramaris-Vrantsis et al., 2007; Matsumoto et al., 2004; Torelli et al., 2005), leading to loss of function though cellular mislocalization from the Golgi, the cellular compartment where FKRP exerts its function. The functional potential of these ER-retained mutant proteins if properly rescued to the Golgi has not been assessed, a crucial characteristic to determine at the time when pharmacological treatments aiming to target the ERQC and ERAD systems are envisaged for patients. Beside these cases, other FKRP genetic variants were shown to be correctly localized in the Golgi compartment, some of which being implicated in severe phenotypes such as WWS (Keramaris-Vrantsis et al., 2007). The underlying explanation of the discrepancies between the correct localization and the severity of the phenotype has not been elucidated.

In this study, we addressed the current gap in knowledge about the functional potential of mutant proteins bearing some of the most common FKRP patient genetic variants. We developed heterologous models, which permitted the investigation of the subcellular localization and functional status of the disease-causing FKRP mutated proteins. We demonstrated that genetic variants that areobserved to be retained in the ER can nevertheless be able to overcome this retention and present activity levels comparable to wild-type-activity. In addition, we observed that some of the FKRP mutant proteins that correctly localize in the Golgi present either no or severely impaired function, indicating that the pathological mechanism of these FKRP genetic variants might corresponds to a direct perturbation of the enzymatic function whereas the mutated protein is considered normal by the QC. Taken 
together, this data has can bring important implications for the development of therapeutic strategies in FKRP deficiencies for which there is still no curative treatment, more specifically for patients affected by genetic variants leading to ER-retained but nonetheless functional proteins.

\section{Materials and methods}

2.1 Cloning and mutagenesis. The FKRP fusion protein comprising the human FKRP CCDS (Gene ID: 79147, NM_001039885.2, CCDS12691.1), the prototypical FLAG sequence (DYKDDDDK), a flexible type linker (3xGGGGS) (Chen, Zaro, \& Shen, 2013) and a mCherry fluorescent reporter sequence was synthesized and codon-optimized for human expression by GENEWIZ. The transgene was inserted into a lentivirus backbone plasmid under the transcriptional control of the CMV promoter. The final construct was named FKRPmCh. Mutagenesis was performed in FKRPmCh plasmid using the QuickChange XL Mutagenesis Kit (Agilent) according to the supplier's protocol with the mutant constructs differing from the wild-type only by the modification of the codon of the genetic variant.

2.2 Cell culture. Near-haploid human HAP1 cells are commercialized by Horizon Discovery $^{\mathrm{TM}}$. The HAP1 FKRP $_{\mathrm{KO}}$ cell line, bearing a 17 base-pair (bp) deletion in the endogenous FKRP gene, was available off-the-shelf (Product ID: HZGHC000726c009). The cells were grown in Iscove's Modified Dulbecco's Medium (IMDM) (Thermo Fisher Scientific) with $10 \%$ fetal bovine serum (FBS) (Thermo Fisher Scientific) and $10 \mu \mathrm{g} / \mathrm{ml}$ of Gentamicin (Thermo Fisher Scientific) and incubated at $37^{\circ} \mathrm{C}$ and atmospheric humidity of $5 \% \mathrm{CO}_{2}$. Cells were mycoplasma negative. 
2.3 Transfections and transductions. Cells were seeded in six or twelve well-plates at $60 \%$ confluence. Cells used for immuno-fluorescence (IF) staining were seeded on glass coverslips in the bottom of the well. Transfection of FKRPmCh plasmids were conducted using Turbofectin 8.0 reagent (Origene) for $48 \mathrm{~h}$ accordingly to the supplier's protocol and a Turbofectin/DNA ratio of 3: 1 with the same DNA concentrations. Transduction of lentiviral particles expressing FKRPmCh WT or mutant constructs were performed at multiplicity of infection (MOI) of three and in combination with Polybrene (6ug/mL; Sigma-Aldrich). Incubation with the viral particles was performed for $18 \mathrm{~h}$ at $37^{\circ} \mathrm{C}$ and $5 \% \mathrm{CO}_{2}$, after which the medium was replaced and the cells were kept at $37^{\circ} \mathrm{C}$ until further analysis.

2.4 Immuno-fluorescence confocal staining, acquisition and analysis. The IF staining for confocal microscopy was performed as follows: the cells were fixed in formaldehyde $3.7 \%$ (Sigma-Aldrich) for 15 minutes at room temperature. If permeabilization was required, Triton $\mathrm{X}-100 \quad 0.5 \%$ (Sigma-Aldrich) was used for $5 \mathrm{~min}$ at room temperature. Saturation was performed in PBS 20\% foetal bovine serum (FBS) for $1 \mathrm{~h}$ at room temperature. The primary antibodies Calnexin (Rabbit, ab22595, Abcam), GM130 (Mouse, 610822, BD-Biosciences), TGN46 (Sheep, AHP500GT, BioRad), a-dystroglycan (IIH6; Mouse, sc-53987, Santa Cruz Biotechnology), $\beta$-integrin (Mouse, sc-13590, Santa Cruz Biotechnology) or Wheat Germ Agglutinin (WGA-Alexa Fluor ${ }^{\mathrm{TM}} 488$ Conjugate, W11261, Thermo Fisher Scientific) were added in the appropriate dilutions in PBS 2\% FBS for $3 \mathrm{~h}$ at room-temperature or over-night at $4^{\circ} \mathrm{C}$. After three washes with PBS for 5 minutes, incubation with secondary antibodies Alexa Fluor ${ }^{\mathrm{TM}}-488$ and Alexa Fluor ${ }^{\mathrm{TM}}-594$ fluorescent-conjugated antibodies (Thermo Fisher Scientific) was performed in PBS 2\% FBS for $1 \mathrm{~h}$ at room-temperature in the dark. Three washes with PBS for 5 minutes were performed and the glass slides were mounted in DAPI Fluoromount-G ${ }^{\circledR}$ (CliniSciences) overnight at $4{ }^{\circ} \mathrm{C}$. For the endogenous FKRP protein 
labelling, the fluorescent signal amplification Tyramide SuperBoost Kit (Anti-rabbit Alexa Fluor ${ }^{\mathrm{TM}}-488$, B40922, Thermo Fisher Scientific) was used accordingly to the supplier's protocol. Confocal images were taken using the Leica SP8 confocal microscope (Leica) at either the 40X, $63 \mathrm{X}$ or $100 \mathrm{X}$ oil-objectives. Bright-field images were taken using the Evos microscope (Thermo Fisher Scientific) at a 40X objective. Images were treated and analysed using ImageJ/Fiji software (Schindelin et al., 2012) and the Pearson's coefficients of correlation were calculated using the JACoP plugin (Bolte \& Cordelieres, 2006).

2.5 Flow cytometry staining, acquisition and analysis. The staining for flow cytometry was performed as follows: saturation was performed in cold PBS 2\% FBS + human FcR blocking agent (Miltenyi Biotec) for 20 minutes at $4^{\circ} \mathrm{C}$. The primary antibody $\alpha$-dystroglycan (IIH6; Mouse, sc-53987, Santa Cruz Biotechnology) was diluted at a ratio 1/20 in cold PBS 2\% FBS and incubated for 20 minutes at $4^{\circ} \mathrm{C}$. After one wash with cold PBS, incubation with the Goat anti-Mouse Alexa Fluor ${ }^{\mathrm{TM}}-488$ fluorescent-conjugated secondary antibody (Thermo Fisher Scientific) was performed in PBS $2 \%$ FBS for 20 minutes at $4{ }^{\circ} \mathrm{C}$ in the dark. Three washes with cold PBS were performed and the final cell pellets were ressuspended in cold PBS $2 \%$ FBS and kept in ice until further analysis. Positive (HAP1-WT) and negative (secondary

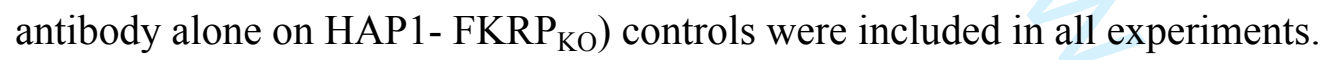

The CytoFLEX flow cytometer (Beckman Coulter) and the B525/40 BP (A488) and Y610/20 BP (mCherry) lasers were used with the same settings for all experiments. Flow cytometry data was treated and analysed using the Kaluza analysis software (Beckman Coulter). Flow cytometry values are presented as the integrated Mean Fluorescence Intensity (iMFI). iMFI is calculated as the MFI multiplied by the percentage of positive cells for the glycosylation (IIH6) signal within the mCherry positive cell population which equals correctly transfected cells. The iMFI $\alpha$-DG glycosylation values of patient fibroblasts by flow cytometry were 
shown to be closely related to the glycosylation levels in the corresponding muscle biopsies (Stevens et al., 2013). Flow cytometry values were normalized against the transduced FKRP WT construct in each independent experiment.

2.6 Prediction of functional impact of FKRP variants. The online predictor tools Polymorphism Phenotyping v2 (PolyPhen-2 (Adzhubei et al., 2010), http://genetics.bwh.harvard.edu/pph2/), Protein Variation Effect Analyzer (PROVEAN (Choi, Sims, Murphy, Miller, \& Chan, 2012), http://provean.jcvi.org/seq_submit.php) and MutationAssessor release 3 ((Reva, Antipin, \& Sander, 2011), http://mutationassessor.org/r3/) were used at the last current version (March 2019) and run with the default settings.

2.7 Data and statistical analysis. The GraphPad PRISM 7.01 program (GraphPad Software Inc.) was used for calculating statistics using unpaired t-test. The results represent the average \pm SEM of at least three independent experiments (cell culture, transfection/transduction and analysis performed in different days). P-values were calculated using the WT as control and P $<0.05$. Regression curves were calculated using a centred second order polynomial (quadratic) equation with ordinary fit parameters. $n s=$ non-significant, $* \mathrm{p} \leq 0.05, * * \mathrm{p} \leq 0.01, * * * \mathrm{p} \leq 0.001$, $* * * * \mathrm{p} \leq 0.0001$

\section{Results}

\subsection{Cellular model validation}

In order to study the cellular consequences of FKRP patient genetic variants in vitro, we took advantage of the near-haploid HAP1 cell line as these cells were previously shown to support 
the complete $\alpha$-DG chain of glycosylation (Endo et al., 2015; Riemersma et al., 2015). To avoid interference by the endogenous FKRP protein, a CRISPR/Cas9-induced FKRP knockout $(\mathrm{KO})$ cell line was used (HAP1-FKRP $\mathrm{KO}_{\mathrm{KO}}$ ). Validation of the cellular model was performed by FKRP immuno-labelling and $\alpha$-DG glycosylation staining. Using an immuno-fluorescence (IF) amplification system, we demonstrated the absence of endogenous FKRP protein in the HAP1-FKRP $_{\text {KO }}$ cells whereas the signal co-localized with the Golgi markers (GM130 and TGN46 for cis- and trans-Golgi respectively) in the HAP1-WT cell line as expected (Figure 1A). The HAP1-FKRP ${ }_{\text {KO }}$ cell line, while presenting normal cell growth, was characterized by small cytoplasmic volume and membrane disturbances, specifically deficiency in filipodia, as detected by membrane staining for $\beta$-integrin and Wheat Germ Agglutinin (WGA) (Figure 1B). IF and flow-cytometry analysis showed a substantial reduction of the functional $\alpha$-DG glycosylation at the cell membrane based on the IIH6 specific antibody (Figure 1C), confirming the absence of FKRP activity in HAP1-FKRP ${ }_{\mathrm{KO}}$ cells and the utility of using this cell line for FKRP mutant protein characterization.

To be able to select the exogenous FKRP positive cells in flow cytometry experiments and to directly detect the protein in cellular localization experiments without the need of antibodies, we generated a fluorescently labelled fusion protein. This protein consists of the human FKRP coding sequence fused, at its C-terminus and through a flexible linker, to a mCherry $(\mathrm{mCh})$ fluorescent reporter protein (FKRPmCh). IF staining experiments demonstrated the integrity of the fusion protein since the mCherry signal co-localized with the labelling for FKRP and with the trans-Golgi marker TGN46 (Supp. Figures S1A and S1B). In addition, only the mCherry positive cells were positive for membrane staining with the IIH6 antibody in nonpermeabilized conditions (Supp. Figure S1C), indicating that the addition of the fluorescent 
reporter did not alter the normal cellular localization and function of the WT FKRP protein and that the construct could be used further for genetic variants characterization.

\subsection{Cellular localization of FKRP mutant proteins}

With the aim of characterizing FKRP mutant proteins using our overexpression system, we chose to test seven missense patient genetic variants associated with pathologies ranging from the severe CMD to the mild LGMD2I and localized throughout the entire length of the protein (Table 1A). In addition to the patient genetic variants, two control mutants were used. In the first, the di-Arginine (R) motif at positions 2 and 5 (R2R5) responsible for the Golgi positioning was mutated to Glutamic acid (E) residues (E2E5). In the second, the catalytic residues composed of two Aspartic acids (D) and a Valine (V) in positions 362-364 (DvD) were mutated into asparagine residues $(\mathrm{N})(\mathrm{NNN})$. The first mutant protein was previously described as being unable to traffic from the ER to the Golgi, whereas the second was shown to abrogate the enzymatic activity of FKRP (Esapa et al., 2002).

When overexpressed in HAP1-FKRP ${ }_{\text {Ко }}$ cells, the different constructs presented three different profiles. The WT construct co-localized with the trans-Golgi, as well as the L276I, NM_001039885.2:p.Tyr182Cys (Y182C) and NM 001039885.2:p.Val300Ala (V300A) mutant proteins (Figure 2A). The mCherry signal of the E2E5 and NM_001039885.2:p.Val405Leu (V405L) mutants presented a cytoplasmic localization, later confirmed to co-localize with the ER marker calnexin (CNX) (Supp. Figure S2). Finally, we observed a dual ER/Golgi co-localization for the NNN, NM 001039885.2:p.Ser221Arg (S221R), NM_001039885.2:p.Pro448Leu (P448L) and NM_001039885.2:p.Ala455Asp $(\mathrm{A} 455 \mathrm{D})$ mutant proteins, indicating that these proteins were retained in the ER but were nevertheless able to overcome this retention. Overall, we concluded that, in our system, some 
genetic variants lead to different levels of ER-retention but that evasion from this system is possible for a number of these mutant proteins.

\subsection{Functional analysis of FKRP mutant proteins}

Given that some mutants were co-localized in the Golgi, we tested their protein level and potential for functionality by flow-cytometry using the mCherry and glycosylation signals, respectively (Supp. Figure S3). We observed that the amount of FKRPmCh protein steadily increased as in the WT for all mutants with the exception of the E2E5, V405L and A455D mutants, suggesting that the presence of the genetic variant may leads to protein instability (Figure 2B). As expected, the increase of FKRPmCh amount was associated with an increase in $\alpha$-DG functional glycosylation for the WT in the mCherry positive population. The Y182C and L276I mutants led to the same glycosylation levels than the WT, demonstrating a fully functional capacity, whereas the S221R, P448L and A455D, although displaying a slower increase, soon caught up with WT functional levels at 45h (Supp. Figure S4). The reduced level of glycosylation observed for the V405L is probably related to the low level of the protein. The NNN mutant control was functionally fully impaired as predicted since corresponding to a catalytically dead enzyme while the E2E5 mutant displayed a marked functional reduction most likely due to the impaired traffic to the Golgi compartment as demonstrated in the IF staining. Remarkably, the V300A mutant protein, which was correctly localized in the Golgi apparatus, displayed a striking reduced level of glycosylation, indicating that, although the protein is able to traffic correctly, it fails to extend the $\alpha$-DG glycosylation moiety. Taken together, our results showed that overexpression of FKRP mutant proteins in the HAP1-FKRP ${ }_{\mathrm{KO}}$ cell line can be used to study the localization and the function potential of FKRP mutant proteins. Additionally, we showed that characterization of cellular localization alone is not sufficient to infer protein function. 


\subsection{Characterization of FKRP patient genetic variants localized between residues 300} and 328

We were intrigued about the functional impairment induced by V300A, which is located at the beginning of the predicted catalytic domain (Alhamidi et al., 2011). The corresponding mutant protein did not present signs of ER-retention nor was its protein level low by flow cytometry, indicating that the protein was not identified by the QC/ERAD systems as misfolded. Yet, this protein was not able to function properly, i.e. glycosylation of $\alpha$-DG, despite the mutated residue not being localized in the DvD catalytic core residues (positions 362-364). We decided to investigate further the cellular localization and function of other genetic variants positioned downstream of the 300 Valine residue and in the beginning of the catalytic domain based on the published FKRP model (Alhamidi et al., 2011). For this purpose, we generated 14 additional patient genetic variants present between residues 300 and 328 of the FKRP protein (Table 1B). Our mutant panel included NM_001039885.2:p.Tyr307Asn (Y307N) and NM_001039885.2:p.Cys318Tyr (C318Y), previously characterized to be localized in the Golgi in other cell types (Dolatshad et al., 2005; Torelli et al., 2005). The associated phenotypes encompassed all severities, with the majority of genetic variants being reported in the Leiden Muscular Dystrophy database only one or two times.

The IF staining demonstrated that, alike the V300A mutant, all these additional FKRP mutant proteins, to the exception of the NM 001039885.2:p.Tyr328Ser (Y328S), co-localized with the Golgi apparatus (Figure 3A). Regarding protein function, all the tested genetic variants presented reduced levels of function compared with the WT (Figure 3B), with four mutants, NM_001039885.2:(p.Pro305Leu (P305L), Y307N, NM_001039885.2:p.Thr314Pro (T314P) and $\mathrm{C} 318 \mathrm{Y}$ presenting functional levels close to the catalytically dead NNN mutant. We could 
also observe that the nature of the amino-acid modification, in addition to the amino-acid position, also impacted the function, as the same Threonine (T) residue in position 314, when modified to a Methionine (M) was still functional where modification to a Proline (P) abrogated completely the function. The modification of the Proline (P) in position 316 to either Arginine (R), Serine (S) or Threonine (T) did not change dramatically the overall function. All these results indicated that missense mutations localized between residues 300 to 321 of the human FKRP protein, and which we refer to $\mathrm{FKRP}_{300-321}$ region, do not seem to induce ER-retention but nevertheless give rise to non-functional or severely impaired mutant proteins in our system. Moreover, four genetic variants abrogated completely the protein function, perhaps indicative of the importance of these residues for the protein activity.

\section{Discussion}

In this study, we evaluated the cellular localization, as well as the level of activity of FKRP proteins bearing genetic variants commonly found in patients using an overexpression system based on the HAP1 FKRP ${ }_{\text {KO }}$ cell line. In this model system, we identified one genetic variant, V405L, which leads to a strict ER localization. Interestingly, this change between the two aliphatic amino acids is quite conservative and is not predicted to overly disrupt the secondary structure of the protein. It is therefore possible that the consequence will pertain on the tertiary or quaternary structure or else the corresponding residue is important for association with a protein implicated in the trafficking to the Golgi. We also identified three mutant proteins, S221R, P448L and A455D, found to be retained in the ER but which were nevertheless able to overcome this retention when overexpressed. This "leakage effect" has been previously described and seen in other misfolded proteins (Gomez-Navarro \& Miller, 
2016; Kawaguchi, Hsu, \& Ng, 2010). Interestingly, these three mutants displayed normal functional levels. Additional mutants that were purely Golgi-resident presented different degrees of defect in enzymatic activity, with a few of them being enzymatically dead (P305L, Y307N, T314P and C318Y), indicating that this particular region is -might be important for the enzymatic activity of FKRP within the Golgi. Finally, some mutants behave similarly to the WT protein (Y182C and L276I) with respect to localization in the Golgi and glycosyltransferase function in our system.

The result obtained with the most frequent FKRP genetic variant L276I, which is well known to be associated with the mildest form of the disease, clearly pinpoints to one of the limitations of our cellular system. Here, the corresponding mutant is undistinguishable to WT whereas we previously showed that it presents a defect in glycosylation function in vivo (Gicquel et al., 2017). Clearly, the high overexpression levels, leading to the exacerbated protein escape from the ER into the Golgi, do notmay not allow the observation of subtle differences induced by this type of genetic variants. We might postulate that the L276I, as well as the Y182C mutant protein, may require extended folding times and be less readily available for the glycosylation process in skeletal muscle context. This hypothesis is supported by the fact that the L276I mutant protein was seen to interact more strongly with CNX, a molecular chaperone of the ER, than the WT (Esapa et al., 2005).

Our data demonstrated-indicates that it is possible to obtain a full functionality with overexpression of proteins that are recognized as being abnormal by the QC as demonstrated by their ER localization. A recent report demonstrated the correct function of the P488L mutant protein in vivo (Tucker, Lu, Xiao, \& Lu, 2018). The authors showed that the mutant protein was able to restore the $\alpha$-DG glycosylation at the muscle membrane and correction of the dystrophic phenotype when overexpressed by adeno-associated virus (AAV) injection in a 
P448L $\mathrm{L}^{\text {neo- }}$ mouse model. In addition, in a more recent study, the same group showed that supplementation of ribitol in drinking water of the $\mathrm{P} 448 \mathrm{~L}^{\text {neo- }}$ mouse increased $\alpha-\mathrm{DG}$ glycosylation (Cataldi, Lu, Blaeser, \& Lu, 2018), indicating that even the endogenous P448L mutant protein present in the mice might still retain some level of functionality. Altogether, these different pieces of evidence support the idea that a pharmacological strategy allowing a bypass of the QC might lead to a therapeutic benefit for patients with the corresponding genetic variants.

Our findings also revealed that patient genetic variants localized within the $\mathrm{FKRP}_{300-321}$ region of the protein, remarkably are all correctly localized in the Golgi but correspond to functionally impaired proteins in our cellular model. Their correct localization indicates that, after protein folding in the ER, the structure of these mutant proteins is possibly qualified as being correctly folded by the QC system and the proteins are allowed to proceed further towards their final destination. However, once in the Golgi, they might do-not have or fail to attain the necessary features for proper function. One can think of incorrect localization within the Golgi apparatus, impossibility to reach an active conformation or dimerization, or impaired interaction with the substrate, the $\alpha-D G$ glycosylation growing chain or additional partners such as FKTN or Transmembrane Protein 5 (TMEM5) protein (Alhamidi et al., 2011; Nishihara et al., 2018). The family of glycosyltransferases (GTs), of which FKRP is a member, encompass enzymes responsible for the transfer of sugar moieties and the formation of glycosidic linkages (Lairson, Henrissat, Davies, \& Withers, 2008). The consensus in the field is that the nucleotide-binding residues of GTs are not restricted to the characteristic DxD motif, but can be also extended to amino-acids localized upstream and downstream of this region (Breton \& Imberty, 1999). While the $\mathrm{FKRP}_{300-321}$ area is not close to the catalytic DxD motif when the amino-acid linear sequence is considered, it is conceivable that this region is 
required for the catalytic function and participate in the catalytic pocket through the 3D conformation. Despite our attempt, no parallel between the prediction of the deleterious score by online predictors and the severity of the disease caused by the FKRP variants was noted (Supp. Table S1). Likewise, no relevant tri-dimensional model was achieved since the results obtained with different prediction softwares were inconsistent. A crystallography model of FKRP protein is then crucial for better understanding the mechanism of enzymatic activation and function and shed a light on the structural consequences arising from the mutated residues. Interestingly, to the exception of the P305L mutant which is associated to an LGMD phenotype, all the identified catalytically "dead" genetic variants are associated with severe phenotypes such as MEB/CMD, LIS and WWS. This information is in support of our findings for the severely impaired function of these mutated proteins and might indicate that a similar phenotype would be present in the human tissue context. Furthermore, patient genetic variants in FKTN, the FKRP homologous protein that shares the same substrate and activity, were described to be correctly localized in the Golgi (Tachikawa et al., 2012) while being functionally impaired, (Kanagawa et al., 2016), reinforcing the relevance of our results.

In conclusion, we propose the following scenario of fate of the different FKRP protein variants, demonstrating suggesting the absence of correlation between the subcellular localization and function of the mutant proteins (Figure 4). Overall, we believe that our experimental approach, integrating the information on the mutant protein cellular localization with its function, is crucialcontributes for the complete understanding of the pathogenic impact of the patient mutation and of the function of the protein. Indeed, we might have uncovered a particular region outside the catalytic motif that seems important for the enzymatic activity of FKRP within the Golgi. Unfortunately, it is difficult to make any conclusions about the severity of the disease based solely on the results obtained in our 
cellular model. It is highly probable that additional factors intervene to explain the phenotype of the variants or combinations of variants. Lastly, the demonstration that the alteration of one amino acid interfering with the proper protein folding process ean-might nevertheless lead to a protein with functionality illustrates can lead to further studies about the potential for the

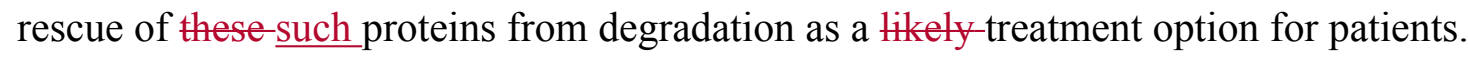

\section{Acknowledgments \\ We would like to thank all the Progressive Muscular Dystrophies group members. We are grateful to the "Imaging and Cytometry Core Facility" of Généthon for technical support and to Genopole Research, Evry, for the purchase of the equipment. The authors have no conflict of interest to declare.}




\section{References}

Adzhubei, I. A., Schmidt, S., Peshkin, L., Ramensky, V. E., Gerasimova, A., Bork, P., .. . Sunyaev, S. R. (2010). A method and server for predicting damaging missense mutations. Nat Methods, 7(4), 248-249. doi: 10.1038/nmeth0410-248

Alhamidi, M., Kjeldsen Buvang, E., Fagerheim, T., Brox, V., Lindal, S., Van Ghelue, M., \& Nilssen, O. (2011). Fukutin-related protein resides in the Golgi cisternae of skeletal muscle fibres and forms disulfide-linked homodimers via an N-terminal interaction. PLoS One, 6(8), e22968. doi: 10.1371/journal.pone.0022968

Barresi, R., \& Campbell, K. P. (2006). Dystroglycan: from biosynthesis to pathogenesis of human disease. J Cell Sci, 119(Pt 2), 199-207.

Beltran-Valero de Bernabe, D. (2004). Mutations in the FKRP gene can cause muscle-eyebrain disease and Walker-Warburg syndrome. Journal of Medical Genetics, 41(5), e61-e61. doi: 10.1136/jmg.2003.013870

Bolte, S., \& Cordelieres, F. P. (2006). A guided tour into subcellular colocalization analysis in light microscopy. $J$ Microsc, 224(Pt 3), 213-232. doi: 10.1111/j.13652818.2006.01706.x

Bouchet, C., Gonzales, M., Vuillaumier-Barrot, S., Devisme, L., Lebizec, C., Alanio, E., .. . Seta, N. (2007). Molecular heterogeneity in fetal forms of type II lissencephaly. Hum Mutat, 28(10), 1020-1027. doi: 10.1002/humu.20561

Breton, C., \& Imberty, A. (1999). Structure/function studies of glycosyltransferases. Curr Opin Struct Biol, 9(5), 563-571.

Brockington, M., Blake, D. J., Prandini, P., Brown, S. C., Torelli, S., Benson, M. A., . . . Muntoni, F. (2001). Mutations in the fukutin-related protein gene (FKRP) cause a form of congenital muscular dystrophy with secondary laminin alpha2 deficiency and abnormal glycosylation of alpha-dystroglycan. [Case Reports

Research Support, Non-U.S. Gov't]. Am J Hum Genet, 69(6), 1198-1209. doi: $10.1086 / 324412$

Carotti, M., Marsolier, J., Soardi, M., Bianchini, E., Gomiero, C., Fecchio, C., . . S Sandona, D. (2018). Repairing folding-defective alpha-sarcoglycan mutants by CFTR correctors, a potential therapy for limb-girdle muscular dystrophy 2D. Hum Mol Genet, 27(6), 969-984. doi: 10.1093/hmg/ddy013

Cataldi, M. P., Lu, P., Blaeser, A., \& Lu, Q. L. (2018). Ribitol restores functionally glycosylated alpha-dystroglycan and improves muscle function in dystrophic FKRPmutant mice. Nat Commun, 9(1), 3448. doi: 10.1038/s41467-018-05990-z 
Chen, X., Zaro, J. L., \& Shen, W. C. (2013). Fusion protein linkers: property, design and functionality. Adv Drug Deliv Rev, 65(10), 1357-1369. doi: 10.1016/j.addr.2012.09.039

Choi, Y., Sims, G. E., Murphy, S., Miller, J. R., \& Chan, A. P. (2012). Predicting the functional effect of amino acid substitutions and indels. PLoS One, 7(10), e46688. doi: 10.1371/journal.pone.0046688

de Paula, F., Vieira, N., Starling, A., Yamamoto, L. U., Lima, B., de Cassia Pavanello, R., .. . Zatz, M. (2003). Asymptomatic carriers for homozygous novel mutations in the FKRP gene: the other end of the spectrum. Eur J Hum Genet, 11(12), 923-930. doi: $10.1038 /$ sj.ejhg.5201066

Dolatshad, N. F., Brockington, M., Torelli, S., Skordis, L., Wever, U., Wells, D. J., . . . Brown, S. C. (2005). Mutated fukutin-related protein (FKRP) localises as wild type in differentiated muscle cells. [Research Support, Non-U.S. Gov't]. Exp Cell Res, 309(2), 370-378. doi: 10.1016/j.yexcr.2005.06.017

Endo, Y., Dong, M., Noguchi, S., Ogawa, M., Hayashi, Y. K., Kuru, S., . . . Nishino, I. (2015). Milder forms of muscular dystrophy associated with POMGNT2 mutations. Neurol Genet, 1(4), e33. doi: 10.1212/nxg.0000000000000033

Ervasti, J. M., \& Campbell, K. P. (1993). A role for the dystrophin-glycoprotein complex as a transmembrane linker between laminin and actin. J Cell Biol, 122(4), 809-823.

Esapa, C. T., Benson, M. A., Schroder, J. E., Martin-Rendon, E., Brockington, M., Brown, S. C., . . . Blake, D. J. (2002). Functional requirements for fukutin-related protein in the Golgi apparatus. Hum Mol Genet, 11(26), 3319-3331.

Esapa, C. T., McIlhinney, R. A., \& Blake, D. J. (2005). Fukutin-related protein mutations that cause congenital muscular dystrophy result in ER-retention of the mutant protein in cultured cells. Hum Mol Genet, 14(2), 295-305. doi: 10.1093/hmg/ddi026

Gerin, I., Ury, B., Breloy, I., Bouchet-Seraphin, C., Bolsee, J., Halbout, M., . . . Bommer, G. T. (2016). ISPD produces CDP-ribitol used by FKTN and FKRP to transfer ribitol phosphate onto alpha-dystroglycan. Nat Commun, 7, 11534. doi: 10.1038/ncomms 11534

Gicquel, E., Maizonnier, N., Foltz, S. J., Martin, W. J., Bourg, N., Svinartchouk, F., . . . Richard, I. (2017). AAV-mediated transfer of FKRP shows therapeutic efficacy in a murine model but requires control of gene expression. Hum Mol Genet, 26(10), $1952-$ 1965. doi: $10.1093 / \mathrm{hmg} / \mathrm{ddx} 066$

Gomez-Navarro, N., \& Miller, E. (2016). Protein sorting at the ER-Golgi interface. J Cell Biol, 215(6), 769-778. doi: 10.1083/jcb.201610031

Guglieri, M., Straub, V., Bushby, K., \& Lochmuller, H. (2008). Limb-girdle muscular dystrophies. Curr Opin Neurol, 21(5), 576-584. doi: 10.1097/WCO.0b013e32830efdc2 
Hohenester, E., Tisi, D., Talts, J. F., \& Timpl, R. (1999). The crystal structure of a laminin Glike module reveals the molecular basis of alpha-dystroglycan binding to laminins, perlecan, and agrin. [Research Support, Non-U.S. Gov't]. Mol Cell, 4(5), 783-792.

Imae, R., Manya, H., Tsumoto, H., Osumi, K., Tanaka, T., Mizuno, M., . . . Endo, T. (2018). CDP-glycerol inhibits the synthesis of the functional O-mannosyl glycan of alphadystroglycan. J Biol Chem, 293(31), 12186-12198. doi: 10.1074/jbc.RA118.003197

Kanagawa, M., Kobayashi, K., Tajiri, M., Manya, H., Kuga, A., Yamaguchi, Y., . . Toda, T. (2016). Identification of a Post-translational Modification with Ribitol-Phosphate and Its Defect in Muscular Dystrophy. Cell Rep, 14(9), 2209-2223. doi: 10.1016/j.celrep.2016.02.017

Kawaguchi, S., Hsu, C. L., \& Ng, D. T. (2010). Interplay of substrate retention and export signals in endoplasmic reticulum quality control. PLoS One, 5(11), e15532. doi: 10.1371/journal.pone.0015532

Kefi, M., Amouri, R., Chabrak, S., Mechmeche, R., \& Hentati, F. (2008). Variable cardiac involvement in Tunisian siblings harboring FKRP gene mutations. Neuropediatrics, 39(2), 113-115. doi: 10.1055/s-2008-1081465

Keramaris-Vrantsis, E., Lu, P. J., Doran, T., Zillmer, A., Ashar, J., Esapa, C. T., . . Lu, Q. L. (2007). Fukutin-related protein localizes to the Golgi apparatus and mutations lead to mislocalization in muscle in vivo. [Research Support, Non-U.S. Gov't]. Muscle Nerve, 36(4), 455-465. doi: 10.1002/mus.20833

Lairson, L. L., Henrissat, B., Davies, G. J., \& Withers, S. G. (2008). Glycosyltransferases: structures, functions, and mechanisms. Annu Rev Biochem, 77, 521-555. doi: 10.1146/annurev.biochem.76.061005.092322

Louhichi, N., Triki, C., Quijano-Roy, S., Richard, P., Makri, S., Meziou, M., . . Fakhfakh, F. (2004). New FKRP mutations causing congenital muscular dystrophy associated with mental retardation and central nervous system abnormalities. Identification of a founder mutation in Tunisian families. Neurogenetics, 5(1), 27-34. doi: $10.1007 / \mathrm{s} 10048-003-0165-9$

Matsumoto, H., Noguchi, S., Sugie, K., Ogawa, M., Murayama, K., Hayashi, Y. K., \& Nishino, I. (2004). Subcellular localization of fukutin and fukutin-related protein in muscle cells. [Research Support, Non-U.S. Gov't]. J Biochem, 135(6), 709-712. doi: $10.1093 / \mathrm{jb} / \mathrm{mvh} 086$

Mercuri, E., Brockington, M., Straub, V., Quijano-Roy, S., Yuva, Y., Herrmann, R., . . . Muntoni, F. (2003). Phenotypic spectrum associated with mutations in the fukutinrelated protein gene. Ann Neurol, 53(4), 537-542. doi: 10.1002/ana.10559

Mercuri, E., Topaloglu, H., Brockington, M., Berardinelli, A., Pichiecchio, A., Santorelli, F., . . Muntoni, F. (2006). Spectrum of brain changes in patients with congenital muscular dystrophy and FKRP gene mutations. Arch Neurol, 63(2), 251-257. doi: 10.1001/archneur.63.2.251 
Nishihara, R., Kobayashi, K., Imae, R., Tsumoto, H., Manya, H., Mizuno, M., . . Toda, T. (2018). Cell endogenous activities of fukutin and FKRP coexist with the ribitol xylosyltransferase, TMEM5. Biochem Biophys Res Commun, 497(4), 1025-1030. doi: 10.1016/j.bbrc.2018.02.162

Quijano-Roy, S., Marti-Carrera, I., Makri, S., Mayer, M., Maugenre, S., Richard, P., .. . Carlier, R. Y. (2006). Brain MRI abnormalities in muscular dystrophy due to FKRP mutations. Brain Dev, 28(4), 232-242. doi: 10.1016/j.braindev.2005.08.003

Reva, B., Antipin, Y., \& Sander, C. (2011). Predicting the functional impact of protein mutations: application to cancer genomics. Nucleic Acids Res, 39(17), e118. doi: 10.1093/nar/gkr407

Richard, I., Laurent, J. P., Cirak, S., \& Vissing, J. (2016). 216th ENMC international workshop: Clinical readiness in FKRP related myopathies January 15-17, 2016 Naarden, The Netherlands. Neuromuscul Disord, 26(10), 717-724. doi: 10.1016/j.nmd.2016.08.012

Riemersma, M., Froese, D. S., van Tol, W., Engelke, U. F., Kopec, J., van Scherpenzeel, M., . . . Lefeber, D. J. (2015). Human ISPD Is a Cytidyltransferase Required for Dystroglycan O-Mannosylation. [Research Support, Non-U.S. Gov't]. Chem Biol, 22(12), 1643-1652. doi: 10.1016/j.chembiol.2015.10.014

Schindelin, J., Arganda-Carreras, I., Frise, E., Kaynig, V., Longair, M., Pietzsch, T., . . . Cardona, A. (2012). Fiji: an open-source platform for biological-image analysis. Nat Methods, 9(7), 676-682. doi: 10.1038/nmeth.2019

Soheili, T., Gicquel, E., Poupiot, J., N'Guyen, L., Le Roy, F., Bartoli, M., \& Richard, I. (2012). Rescue of sarcoglycan mutations by inhibition of endoplasmic reticulum quality control is associated with minimal structural modifications. Hum Mutat, 33(2), 429-439. doi: 10.1002/humu.21659

Stevens, E., Torelli, S., Feng, L., Phadke, R., Walter, M. C., Schneiderat, P., . . . Muntoni, F. (2013). Flow cytometry for the analysis of alpha-dystroglycan glycosylation in fibroblasts from patients with dystroglycanopathies. PLoS One, 8(7), e68958. doi: 10.1371/journal.pone.0068958

Tachikawa, M., Kanagawa, M., Yu, C. C., Kobayashi, K., \& Toda, T. (2012). Mislocalization of fukutin protein by disease-causing missense mutations can be rescued with treatments directed at folding amelioration. [Research Support, Non-U.S. Gov't]. $J$ Biol Chem, 287(11), 8398-8406. doi: 10.1074/jbc.M111.300905

Talts, J. F., Andac, Z., Gohring, W., Brancaccio, A., \& Timpl, R. (1999). Binding of the G domains of laminin alphal and alpha2 chains and perlecan to heparin, sulfatides, alpha-dystroglycan and several extracellular matrix proteins. [Research Support, NonU.S. Gov't]. EMBO J, 18(4), 863-870. doi: 10.1093/emboj/18.4.863

Tisi, D., Talts, J. F., Timpl, R., \& Hohenester, E. (2000). Structure of the C-terminal laminin G-like domain pair of the laminin alpha2 chain harbouring binding sites for alphadystroglycan and heparin. [Comparative Study 
Research Support, Non-U.S. Gov't]. EMBO J, 19(7), 1432-1440. doi: 10.1093/emboj/19.7.1432

Topaloglu, H., Brockington, M., Yuva, Y., Talim, B., Haliloglu, G., Blake, D., .. . Muntoni, F. (2003). FKRP gene mutations cause congenital muscular dystrophy, mental retardation, and cerebellar cysts. Neurology, 60(6), 988-992.

Torelli, S., Brown, S. C., Brockington, M., Dolatshad, N. F., Jimenez, C., Skordis, L., . . . Muntoni, F. (2005). Sub-cellular localisation of fukutin related protein in different cell lines and in the muscle of patients with MDC1C and LGMD2I. [Comparative Study

Research Support, Non-U.S. Gov't]. Neuromuscul Disord, 15(12), 836-843. doi: 10.1016/j.nmd.2005.09.004

Tucker, J. D., Lu, P. J., Xiao, X., \& Lu, Q. L. (2018). Overexpression of Mutant FKRP Restores Functional Glycosylation and Improves Dystrophic Phenotype in FKRP Mutant Mice. Mol Ther Nucleic Acids, 11, 216-227. doi: 10.1016/j.omtn.2018.02.008

von der Hagen, M., Kaindl, A. M., Koehler, K., Mitzscherling, P., Hausler, H. J., StoltenburgDidinger, G., \& Huebner, A. (2006). Limb girdle muscular dystrophy type 2I caused by a novel missense mutation in the FKRP gene presenting as acute virus-associated myositis in infancy. Eur J Pediatr, 165(1), 62-63. doi: 10.1007/s00431-005-1752-6

Wahbi, K., Meune, C., Hamouda el, H., Stojkovic, T., Laforet, P., Becane, H. M., . . Duboc, D. (2008). Cardiac assessment of limb-girdle muscular dystrophy 2I patients: an echography, Holter ECG and magnetic resonance imaging study. Neuromuscul Disord, 18(8), 650-655. doi: 10.1016/j.nmd.2008.06.365

Walter, M. C., Petersen, J. A., Stucka, R., Fischer, D., Schroder, R., Vorgerd, M., . . . Lochmuller, H. (2004). FKRP (826C $>$ A) frequently causes limb-girdle muscular dystrophy in German patients. J Med Genet, 41(4), e50.

Yamamoto, L. U., Velloso, F. J., Lima, B. L., Fogaca, L. L., de Paula, F., Vieira, N. M., .. . Vainzof, M. (2008). Muscle protein alterations in LGMD2I patients with different mutations in the Fukutin-related protein gene. J Histochem Cytochem, 56(11), 9951001. doi: 10.1369/jhc.2008.951772 


\section{Figure legends}

Figure 1. Cellular characterization of HAP1 WT and HAP1 FKRP-KO cell lines. (A) Cellular morphology and endogenous FKRP cellular localization. Endogenous FKRP protein was detected in HAP1 WT cells (top panels), where the signal co-localized with the cis-Golgi Marker GM130 and the trans-Golgi marker TGN46, and was absent at these locations in HAP1 FKRP ${ }_{\text {KO }}$ cells (bottom panels). Nuclei are labelled by DAPI staining. Scale bars: $30 \mu \mathrm{m}$ (bright-field), $10 \mu \mathrm{m}$ (fluorescence). (B) Small cytoplasmic volume and perturbed membrane morphology in HAP1 FKRP KO cells was observed compared to the HAP1 WT control cell line, based on the IF against membrane $\beta$-integrin and WGA. Image magnifications are presented in the right panels. Nuclei are labelled by DAPI staining. Scale bars: $20 \mu \mathrm{m}$ and $10 \mu \mathrm{m}$ for zooms (C) Characterization of $\alpha$-DG functional glycosylation in the two cell lines. The specific glycosylation, detected through the IIH6 antibody, was present in HAP1 WT but not in HAP1 FKRP KO as observed by confocal imaging. (D) Flow cytometry quantification of $\alpha$-DG functional glycosylation of HAP1-WT and HAP1 FKRP KO labelled with secondary antibody alone (II) or in combination with IIH6 primary antibody against $\alpha$-DG functional glycosylation $(\mathrm{I}+\mathrm{II}) . * * * * \mathrm{p} \leq 0.0001$

\section{Figure 2. Cellular localization and functional characterization of FKRP mutant proteins}

in HAP1 FKRP KO cells. (A) FKRPmCh mutant proteins cellular localization after IF for the trans-Golgi compartment (TGN46). Nuclei are labelled by DAPI staining. Scale bar: $5 \mu \mathrm{m}$. (B) Functional characterization of FKRP mutant proteins through detection of $\alpha$-DG functional glycosylation after lentivirus transduction in HAP1 FKRP KO cells. In this condition, the low copy number achieved allows observation along time. The levels of the specific $\alpha$-DG glycosylation, as well as the levels of mCherry signal as a measure of 
FKRPmCh protein production, were followed and quantified through time. The levels of glycosylation were assessed only for the mCherry positive population representing the successfully transfected cells. Data is presented as the integrated Mean Fluorescence Intensity $(\mathrm{iMFI}=$ MFI $* \%$ positive cells) values in arbitrary units (A.U.) within this mCherry population.

Figure 3. Cellular localization and functional characterization of FKRP proteins with missense mutations localized between residue 300 and 328. (A) FKRPmCh mutant proteins cellular localization by IF for the trans-Golgi compartment (TGN46) after transfection in HAP1 FKRP KO cells. The mCherry signal of the fusion proteins specifically co-localized with the trans-Golgi for FKRP WT and all the mutants within residue 300 and 321. Mutant Y328S displayed a trans-Golgi co-localization as well as a cytoplasmic signal corresponding to the ER. Nuclei are labelled by DAPI staining. Scale bar: $5 \mu \mathrm{m}$. (B) Functional characterization of FKRP mutant proteins through detection of $\alpha$-DG functional glycosylation after transfection in HAP1 FKRP KO cells. The levels of glycosylation were assessed only for the mCherry positive population representing the successfully transfected cells. The functional level of the catalytically dead NNN mutant protein is represented as a dashed line. Data is presented as relative iMFI (MFI * \% positive cells) values in arbitrary units (A.U.). ns $=$ non-significant, ${ }^{*} \mathrm{p} \leq 0.05, * * \mathrm{p} \leq 0.01, * * * \mathrm{p} \leq 0.001, * * * * \mathrm{p} \leq 0.0001$.

Figure 4. Graphic model depicting the-proposed steps and final outcomes of normal and abnormal FKRP protein folding/function in physiological conditions in vivo. (A) Normal physiological condition. 1) FKRP is correctly folded in the ER; 2) FKRP is trafficked to the trans-Golgi; 3) FKRP transfers Rbo-5P to $\alpha$-DG glycosylation chain; 4) $\alpha$-DG is functionally glycosylated at the membrane; 5) Correct ECM binding ensures sarcolemma integrity. (B) Patient with missense mutation in FKRP- protein is retained in the ER. 1) Mutation in FKRP 
lead to ER-retained misfolded protein; 2) FKRP protein is not able to traffic correctly to the Golgi; 3) The $\alpha$-DG glycosylation chain is not extended; 4) Defects in ECM binding lead to membrane fragility and muscle dystrophy. (C) Patient with missense mutation in FKRPprotein is not functionally active. 1) FKRP is correctly folded in the ER; 2) FKRP is trafficked to the trans-Golgi; 3) FKRP does not achieve functional conformation in the Golgi and fails to transfers Rbo-5P to $\alpha$-DG glycosylation chain; 4) The $\alpha$-DG glycosylation chain is not extended; 5) Defects in ECM binding lead to membrane fragility and muscle dystrophy. 
Table 1. Description of the studied FKRP patient variants. The information presented includes the associated pathology, number of case reports and the corresponding references (Leiden Muscular Dystrophy pages; www.dmd.nl/). (A) FKRP missense mutants used in the subcellular localization and functional studies. (B) FKRP missense mutations localized between protein residues 300 and 328. The human FKRP gene (Gene ID: 79147, NM_001039885.2, CCDS12691.1) is used and gene variants are described using HGVSnomenclature (http://varnomen.hgvs.org). $\mathrm{CMD}=$ Congenital Muscular Dystrophy, MEB = Muscle-Eye-Brain disease, WWS = Walker-Warburg Syndrome, LIS = Lissencephaly, LGMD2I = Limb-Girdle Muscular Dystrophy type 2I.

A.

\begin{tabular}{|c|c|c|c|}
\hline Human genetic variants & Pathology $\dagger$ & \# Reports $\dagger$ & References \\
\hline 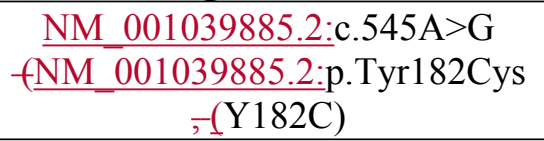 & LGMD2I & 6 & $\begin{array}{l}\text { (de Paula et al., 2003; Wahbi } \\
\text { et al., 2008; Yamamoto et al., } \\
\text { 2008) }\end{array}$ \\
\hline $\begin{array}{c}\text { NM 001039885.2:c.663C }>\text { A } \\
\text { NM 001039885.2:(p.Ser221Arg }\end{array}$ & CMD & 2 & $\begin{array}{l}\text { (Mercuri et al., 2006; } \\
\text { Topaloglu et al., 2003) }\end{array}$ \\
\hline $\begin{array}{c}\text { NM 001039885.2:c.826C }>\text { A } \\
\frac{\text { NM 001039885.2:(p.Leu276Ile }}{\text { (L276I) }}\end{array}$ & LGMD2I & 240 & Several reports \\
\hline $\begin{array}{c}\frac{\mathrm{NM} \text { 001039885.2:c.899T }>\mathrm{C}}{\mathrm{NM} \text { 001039885.2:(p.Val300Ala }} \\
\text { (V300A) }\end{array}$ & LGMD2I & 5 & $\begin{array}{l}\text { (de Paula et al., 2003; Walter } \\
\text { et al., 2004; Yamamoto et al., } \\
\text { 2008) }\end{array}$ \\
\hline $\begin{array}{l}\frac{\mathrm{NM} \text { 001039885.2:c.1213G }>\mathrm{T}}{\mathrm{NM} 001039885.2:(p . V a 1405 \mathrm{Leu}}- \\
\text { (P405LV405L) }\end{array}$ & CMD & 1 & (Louhichi et al., 2004) \\
\hline $\begin{array}{l}\frac{\mathrm{NM} \text { 001039885.2:c.1343C }>\mathrm{T}}{\text { NM 001039885.2:(p.Pro448Leu, }} \\
\text { (P448L) }\end{array}$ & CMD & 3 & $\begin{array}{l}\text { (Brockington et al., 2001; } \\
\text { Dolatshad et al., 2005; } \\
\text { Mercuri et al., 2003) }\end{array}$ \\
\hline $\begin{array}{l}\frac{\mathrm{NM} 001039885.2: \mathrm{c} .1364 \mathrm{C}>\mathrm{A}}{\mathrm{NM} 001039885.2:(\mathrm{p} . \text { Ala455Asp }} \\
\text { (A455D) }\end{array}$ & LGMD2I/CMD & 14 & $\begin{array}{c}\text { (Louhichi et al., 2004) (Kefi, } \\
\text { Amouri, Chabrak, } \\
\text { Mechmeche, \& Hentati, 2008; }\end{array}$ \\
\hline
\end{tabular}

B.

\begin{tabular}{l|l|l|r} 
Human genetic variants & Pathology $\dagger$ & \# Reports $\dagger$ & References \\
\hline
\end{tabular}




\begin{tabular}{|c|c|c|c|}
\hline  & LGMD2I & 2 & - \\
\hline $\begin{array}{l}\frac{\mathrm{NM} 001039885.2: \mathrm{c} \cdot 919 \mathrm{~T}>\mathrm{A}}{\mathrm{NM} 001039885.2:(\mathrm{p} . T y r 307 \mathrm{Asn}} \\
(\mathrm{Y} 307 \mathrm{~N})\end{array}$ & $\mathrm{MEB} / \mathrm{CMD}$ & 10 & $\begin{array}{l}\text { (Beltran-Valero de Bernabe, } \\
\text { 2004) (Mercuri et al., 2006; } \\
\text { Torelli et al., 2005) (Wahbi et }\end{array}$ \\
\hline $\begin{array}{c}\text { NM_001039885.2:c.926A>G } \\
\text { NM_001039885.2:(p.Tyr309Cys- } \\
\text { (Y309C) }\end{array}$ & - & 1 & $\begin{array}{l}\text { (Brockington et al., 2001; } \\
\text { Mercuri et al., 2003; Torelli et } \\
\text { al., 2005) }\end{array}$ \\
\hline $\begin{array}{l}\frac{\mathrm{NM} 001039885.2: \mathrm{c} .934 \mathrm{C}>\mathrm{T}}{\mathrm{NM} 001039885.2:(\mathrm{p} . A r g 312 \mathrm{Cys}} \overline{-} \\
\text { (R312C) }\end{array}$ & - & 1 & (Brockington et al., 2001) \\
\hline $\begin{array}{l}\frac{\text { NM 001039885.2:c.941C }>\text { T }}{\text { NM 001039885.2:(p.Thr314Met- }} \\
(\text { T314M) }\end{array}$ & CMD/LGMD2I & 6 & - \\
\hline $\begin{array}{l}\frac{\mathrm{NM} \text { 001039885.2:c.940A }>\mathrm{C}}{\mathrm{NM} \text { 001039885.2:p. }} \text { Thr314Pro } \\
\text { (T314P) }\end{array}$ & LIS & 2 & (Bouchet et al., 2007) \\
\hline 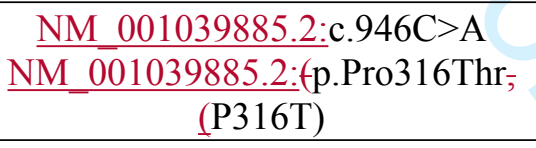 & CMD/LGMD2I & 4 & $\begin{array}{l}\text { (Mercuri et al., 2006; } \\
\text { Topaloglu et al., 2003) }\end{array}$ \\
\hline 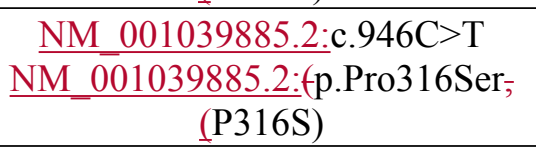 &  & 1 & (Mercuri et al., 2003) \\
\hline $\begin{array}{c}\text { NM 001039885.2:c.947C }>\mathrm{G} \\
\text { NM_001039885.2:(p.Pro316Arg, } \\
\text { (P316R) }\end{array}$ & CMD/LGMD2I & 3 & $\begin{array}{l}\text { (Brockington et al., 2001; } \\
\text { Quijano-Roy et al., 2006) }\end{array}$ \\
\hline $\begin{array}{c}\text { NM_001039885.2:c.953G }>\text { A } \\
\frac{N M \text { 001039885.2:(p.Cys318Tyr; }}{(\text { C318Y })}\end{array}$ & WWS & 2 & $\begin{array}{l}\text { (Beltran-Valero de Bernabe, } \\
\text { 2004) (Mercuri et al., 2006) }\end{array}$ \\
\hline $\begin{array}{l}\frac{\mathrm{NM} 001039885.2: \mathrm{c} \cdot 956 \mathrm{~T}>\mathrm{G}}{\mathrm{NM} 001039885.2:(\mathrm{p} . L e u 319 A r g}{ }_{\overline{5}} \\
\text { (L319R) }\end{array}$ & LGMD2I & & $\begin{array}{c}\text { (Guglieri, Straub, Bushby, \& } \\
\text { Lochmuller, 2008) }\end{array}$ \\
\hline $\begin{array}{c}\text { NM 001039885.2:c.962C>A } \\
\text { NM 001039885.2:(p.Ala321Glu, } \\
\text { (A321E) }\end{array}$ & LGMD2I & 1 & (von der Hagen et al., 2006) \\
\hline $\begin{array}{c}\frac{\mathrm{NM} 001039885.2: \text { c. } 983 \mathrm{~A}>\mathrm{C}}{\mathrm{NM} 001039885.2:\left(\mathrm{p} . T y r 328 \mathrm{Ser}_{\overline{5}}\right.} \\
\text { (Y328S)}\end{array}$ & $\mathrm{CMD} / \mathrm{LGMD} 2 \mathrm{I}$ & 2 & $\begin{array}{l}\text { (Brockington et al., 2001; } \\
\text { Quijano-Roy et al., 2006; } \\
\text { Wahbi et al., 2008) } \\
\end{array}$ \\
\hline
\end{tabular}


A


B
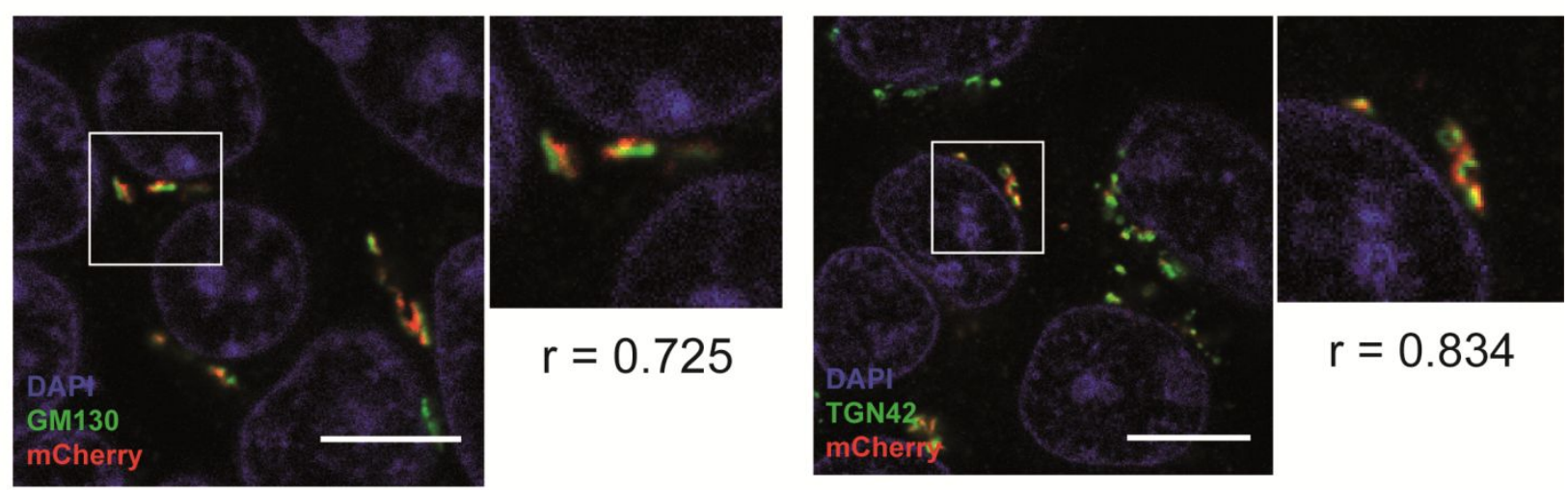

C

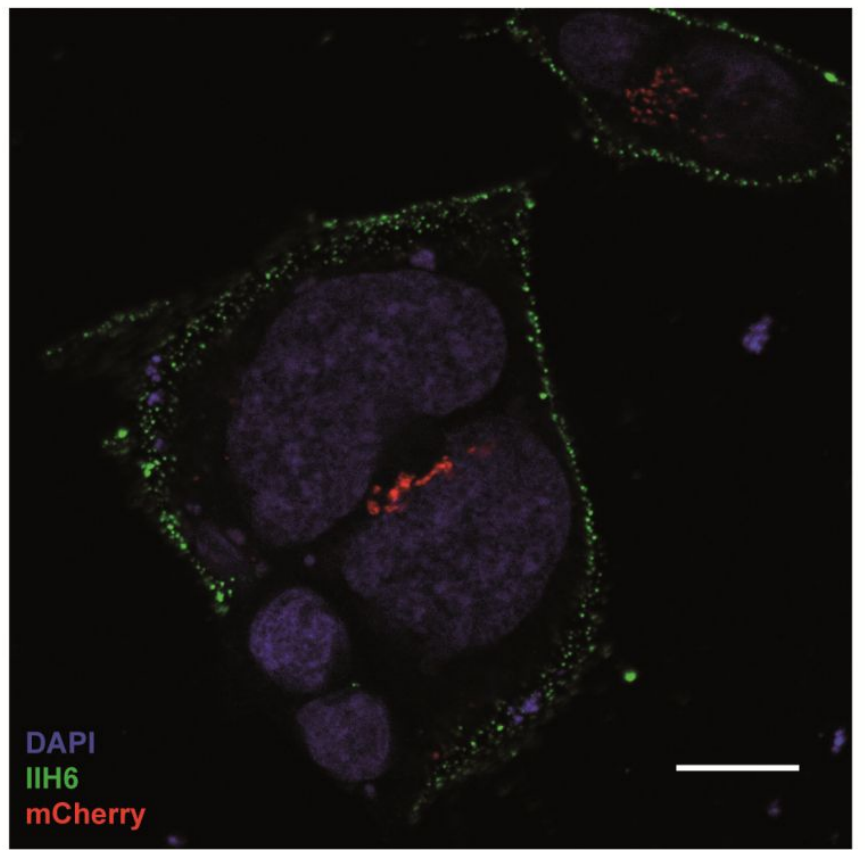

Supp. Figure 1. Characterization of the FKRPmCh fusion protein. 
(A) Correct co-localization of the mCherry signal in the FKRPmCh protein and FKRP labelling confirms the integrity of the fusion protein. Nuclei are labelled by DAPI staining. Scale bar: $5 \mu \mathrm{m}$. (B) Co-localization of the mCherry signal in the FKRPmCh protein with the cis- (GM130) and trans-Golgi (TGN46) labelling confirming that the addition of the mCherry fluorescent reporter did not interfere with the normal FKRP protein traffic. Pearson correlation coefficients between the red (mCh) and green (GM130/TGN46) calculated using the JACoP plugin for ImageJ are presented for the magnified images. Nuclei are labelled by DAPI staining. Scale bar: $10 \mu \mathrm{m}$. (C) Confocal imaging after labelling of $\alpha$-DG functional glycosylation (IIH6) in non-permeabilized conditions and transfection of FKRPmCh-WT in HAP1 FKRP KO cells. Nuclei are labelled by DAPI staining. Scale bar: $10 \mu \mathrm{m}$. 

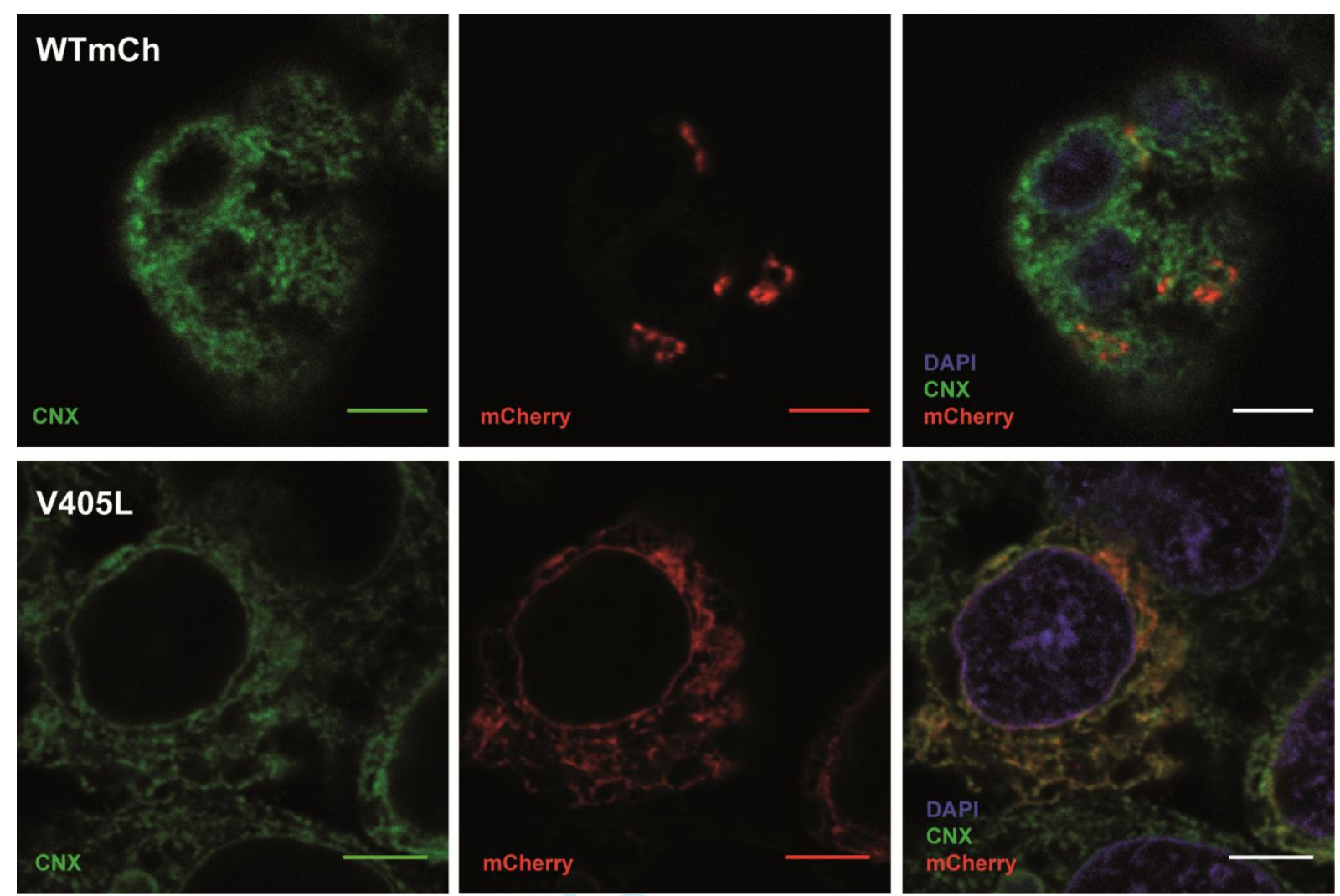

\section{Supp. Figure 2. ER-retention of FKRP mutant proteins.}

FKRPmCh WT and V405L mutant protein cellular localization after IF staining for the ER compartment $(\mathrm{CNX})$. The mCherry signal of the fusion proteins specifically co-localized with the ER for FKRP V405L, as an example, confirming that the cytoplasmic signals observed represents ER-retained mutant proteins. Nuclei are labelled by DAPI staining. Scale bar: $10 \mu \mathrm{m}$. 


+FKRPmCh-WT (I+II)
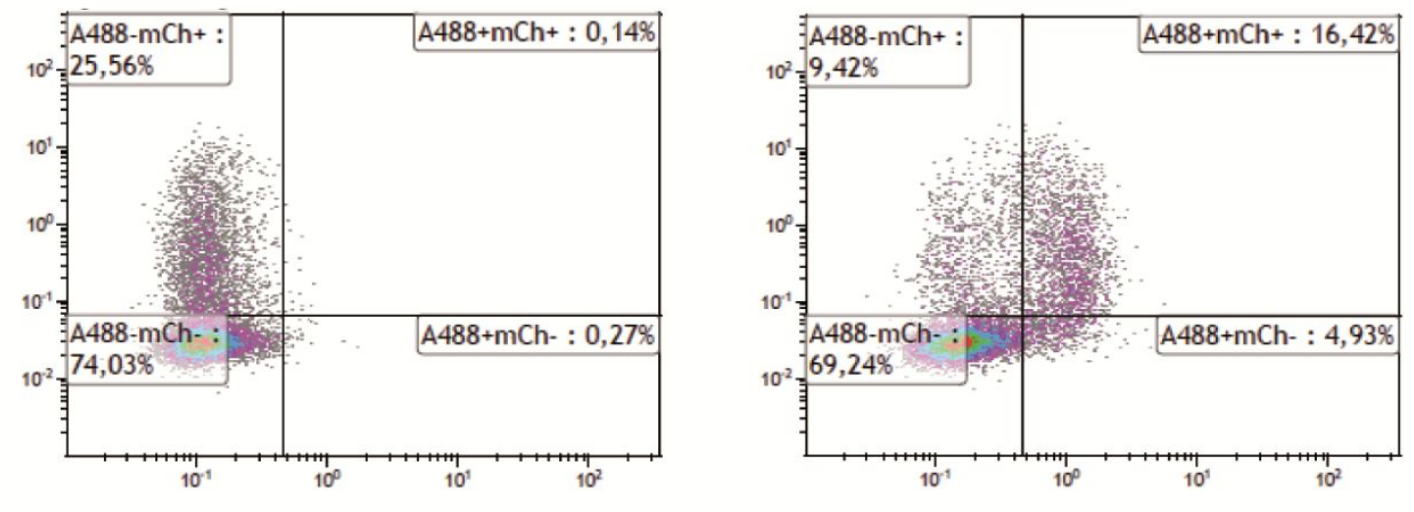

\section{A488}

Supp. Figure 3. Flow cytometry data and gates in HAP1-WT and HAP1 FKRP KO cells. 
Flow cytometry data of HAP1-WT, HAP1 FKRP KO and HAP1 FKRP KO cells transfected with FKRPmCh WT construct labelled with A488 secondary antibody alone (II) or in $\underline{\text { combination with IIH6 primary antibody against } \alpha \text {-DG functional glycosylation (I + II). Cell }}$ gates were defined using the appropriate experimental controls. mCherry (mCh) and A488 signal intensities are shown in axis. The data shows that the intensity of labelling (A488) of the FKRPmCh WT transfected HAP1 FKRP KO cells are in the range of the levels of intensity seen in the HAP1 WT cells (HAP1 WT I+II). 


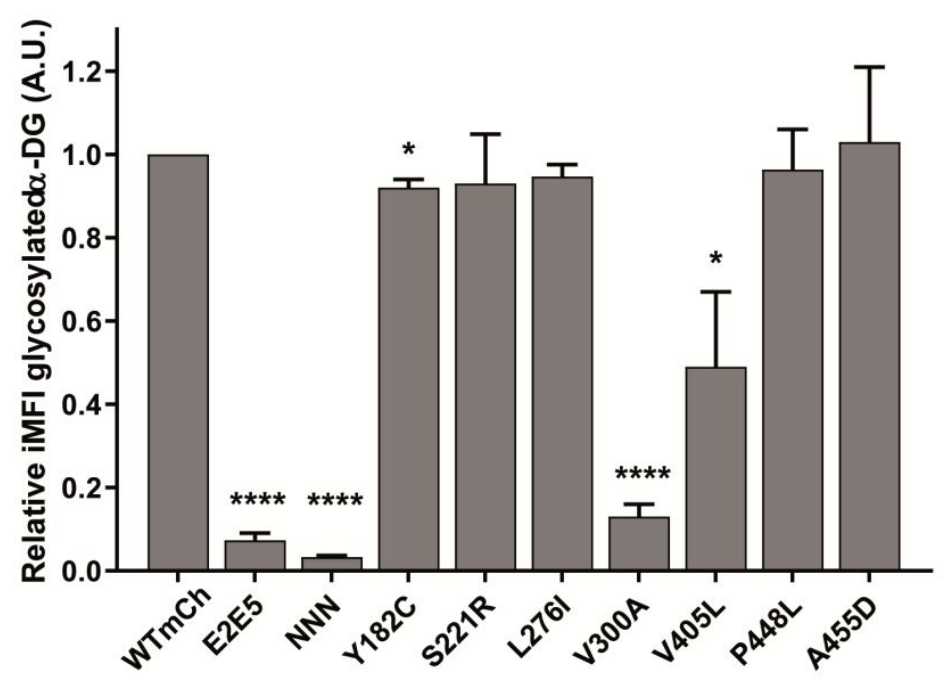

\section{Supp. Figure 34. Function of FKRP mutant proteins at 45h of expression.}

Functional characterization of FKRP mutant proteins through detection of $\alpha$-DG functional glycosylation. Only functional levels at $45 \mathrm{~h}$ are depicted confirming that the mutant proteins, E2E5, V300A and V405L, display levels comparable to the catalytically dead NNN mutant protein. The levels of glycosylation were assessed only for the mCherry positive population representing the successfully transfected cells. Data is presented as relative iMFI (MFI *\% positive cells) values in arbitrary units (A.U.). ns $=$ non-significant, ${ }^{*} p \leq 0.05, * * p \leq 0.01, * * * p$ $\leq 0.001, * * * * \mathrm{p} \leq 0.0001$. 


\begin{tabular}{|c|c|c|c|c|c|}
\hline \multirow{2}{*}{ Variant } & \multirow{2}{*}{$\begin{array}{c}\text { PolyPhen-2 } \\
\text { Prediction }\end{array}$} & \multicolumn{2}{|c|}{ PROVEAN } & \multicolumn{2}{|c|}{ MutationAssessor } \\
\hline & & Prediction & Score & Func. Impact & FI score \\
\hline $\mathrm{Y} 182 \mathrm{C}$ & Benign & Deleterious & -4.767 & Low & 1.385 \\
\hline S221R & Probably damaging & Neutral & -2.367 & Low & 1.445 \\
\hline L276I & Possibly damaging & Neutral & -0.849 & Low & 1.355 \\
\hline V300A & Possibly damaging & Deleterious & -3.219 & Low & 1.87 \\
\hline V405L & Probably damaging & Neutral & -2.372 & Medium & 2.35 \\
\hline P448L & Probably damaging & Deleterious & -8.165 & Medium & 2.465 \\
\hline A455D & Probably damaging & Deleterious & -3.969 & Medium & 2.005 \\
\hline P305L & Probably damaging & Deleterious & -8.796 & Medium & 2.02 \\
\hline Y307N & Probably damaging & Deleterious & -7.733 & Medium & 2.02 \\
\hline Y309C & Probably damaging & Deleterious & -6.507 & Low & 1.87 \\
\hline $\mathrm{R} 312 \mathrm{C}$ & Probably damaging & Deleterious & -5.987 & Low & 1.73 \\
\hline T314M & Probably damaging & Deleterious & -4.744 & Medium & 2.455 \\
\hline T314P & Probably damaging & Deleterious & -5.211 & Medium & 3.005 \\
\hline P316T & Probably damaging & Deleterious & -6.404 & Medium & 3.035 \\
\hline P316S & Probably damaging & Deleterious & -6.404 & Medium & 3.035 \\
\hline P316R & Probably damaging & Deleterious & -7.533 & Medium & 2.69 \\
\hline C318Y & Probably damaging & Deleterious & -9.426 & Medium & 3.14 \\
\hline L319R & Probably damaging & Deleterious & -4.198 & Medium & 2.51 \\
\hline A321E & Probably damaging & Neutral & -1.115 & Low & 1.91 \\
\hline Y328S & Possibly damaging & Deleterious & -3.526 & Low & 1.925 \\
\hline
\end{tabular}

Supp. Table 1. Prediction scores of deleteriousness for FKRP protein variants. The prediction scores of three independent online predictors (PolyPhen-2, PROVEAN and MutationAssessor) are presented for the human FKRP protein with the introduced specific variants. 
Input Errors and warnings AccNo Genesymbol Variant Reference Sequence Start Descr.

Coding DNA Descr. Protein Descr. GeneSymbol Coding DNA Descr. GeneSymbol Protein Descr. Genomic Reference Coding Reference Protein Reference Affected Transcripts Affected Proteins Restriction Sites Created Restriction Sites Deleted

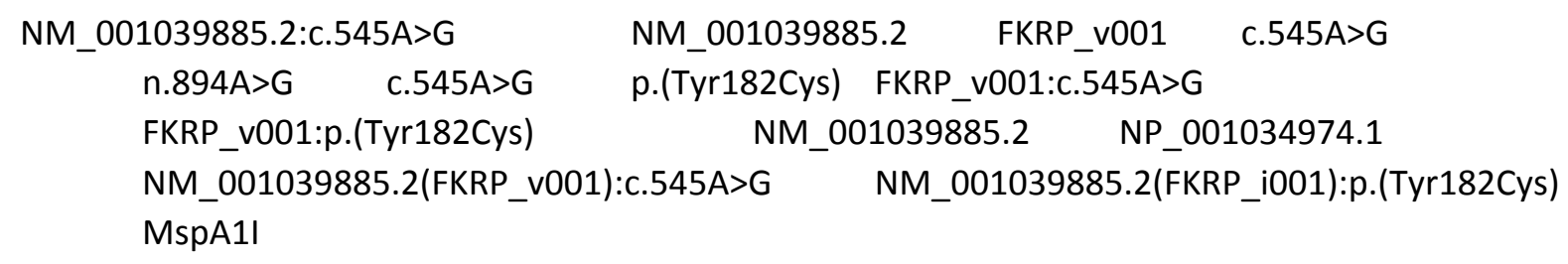









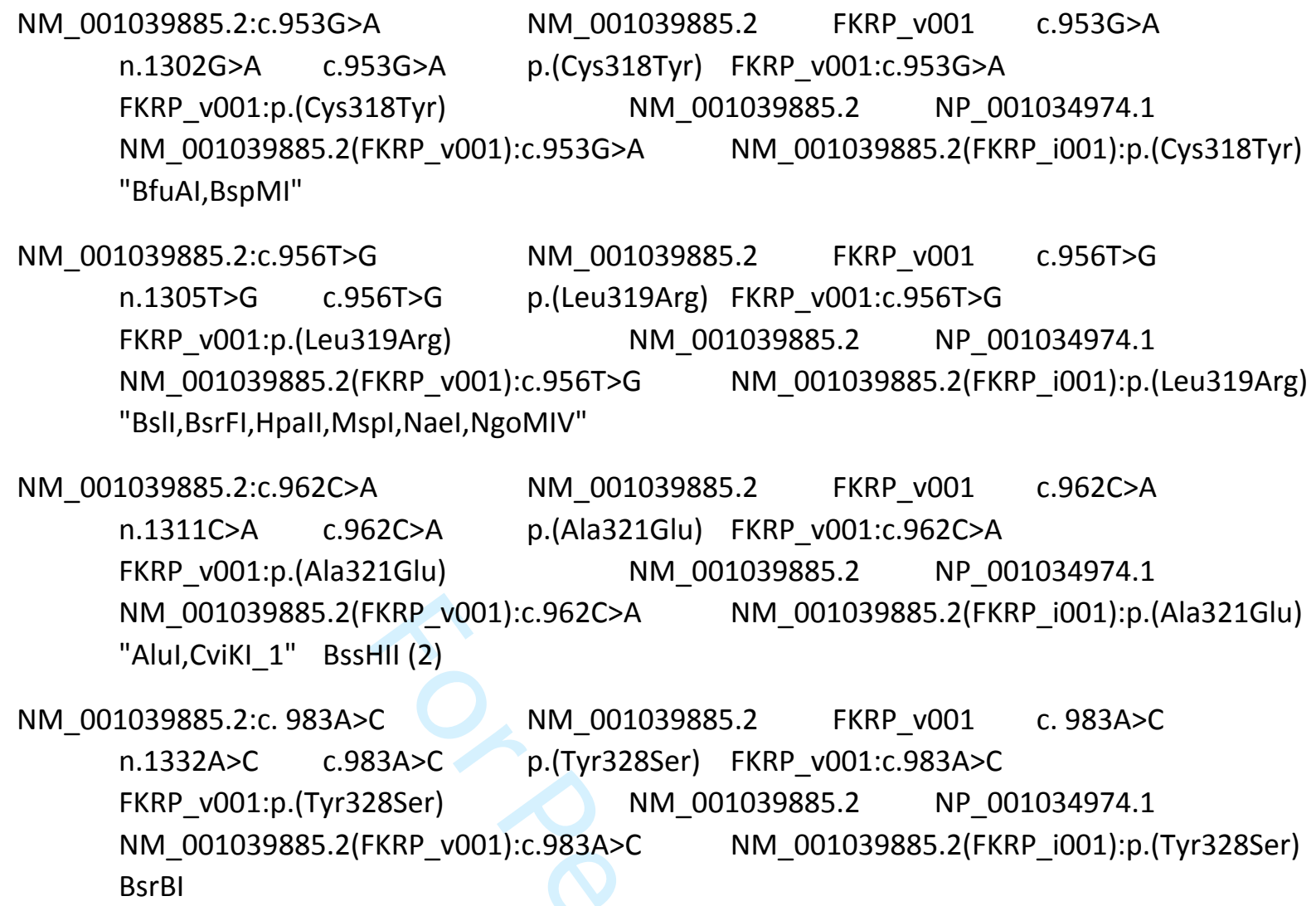

